\title{
A Separate Crime of Reckless Sex
}

\author{
Ian Ayres $\dagger \&$ Katharine K. Baker ††
}

This Article attempts to make progress on the problems of both sexually transmitted disease and acquaintance rape by proposing a new crime of reckless sexual conduct. A defendant would be guilty of reckless sexual conduct if, in a first-time sexual encounter with another person, the defendant had sexual intercourse without using a condom. Consent to unprotected intercourse would be an affirmative defense, to be established by the defendant by a preponderance of the evidence. As an empirical matter, unprotected first-time sexual encounters greatly increase the epidemiological force of sexually transmitted disease, and a substantial proportion of acquaintance rape occurs in unprotected first-time sexual encounters. The new law, by increasing condom use and the quality of communication in first-time sexual encounters, can reduce the spread of sexually transmitted disease and decrease the incidence of acquaintance rape.

Imagine that we wake up one morning to learn that a nineteenyear-old woman has accused a married multimillionaire basketball star ("Star") of raping her at a Colorado resort. Stories from Star's side circulate shortly thereafter claiming that the woman willingly entered Star's room and began consensual sexual contact, but that Star in the midst of vaginal intercourse stopped at the woman's request. ${ }^{1}$

If the case is prosecuted criminally as rape, the prosecution will have to prove much more than that Star failed to stop. In Colorado, which is typical of many states, the prosecution will need to prove, beyond a reasonable doubt, that Star used physical force, threat of physical force, or some kind of intoxicant to cause the victim to submit to intercourse. 2 This is an extraordinarily difficult task. Rape can occur without any signs of physical force, and the kind of bruising that might indicate physical force can accompany purely consensual endeavors. Without any other witnesses, all attempts to prove a threat of physical

$\dagger$ Townsend Professor, Yale Law School.

t† Professor of Law and Associate Dean, Chicago-Kent College of Law.

We thank Jennifer Brown, John Donohue, Steve Heyman, Christine Hurt, Christine Jolls, Edward Kaplan, Barry Nalebuff, Kate Stith, Richard Storrow, and seminar participants at Dickinson, Harvard, Iowa, University of Missouri-Kansas City, and Yale law schools (as well as the Yale Epidemiology and Public Health Department) for comments. Bijal Shah, Praveen Krishna, Tom Sylvester, Steven Wu, and Blake Rohrbacher provided excellent research assistance, and Heidee Stoller provided excellent statistical assistance.

1 For a parallel story, see Allison Samuels, Who Is the Real Kobe, Newsweek 48 (July 28, 2003) (describing the personal problems of Kobe Bryant relating to his rape indictment). In the transcript from the police questioning of Kobe Bryant after an alleged rape at a Colorado resort, Bryant admitted that he was not wearing a condom during his sexual encounter with the alleged victim. See Kobe Bryant Police Interview 21, online at http://thesmokinggun.com/archive/ 0924041 kobea1.html (visited Feb 20, 2005).

2 See Colo Rev Stat Ann § 18-3-402(4)(a)-(d) (West 2004). 
force or the presence of an intoxicant taken under coercion will inevitably devolve into a "he said/she said" contest. ${ }^{3}$ In the end, the jury will be asked whether it is plausible that a possibly star-struck nineteen-year-old consented to sex with a multimillionaire basketball hero. The jury will likely answer yes-because it is plausible. It may not even be likely, but it is probably plausible." If it is plausible that she consented, Star will be acquitted of rape charges.

Good prosecutors are well aware of these difficulties. Many resist bringing rape cases because of them. Other prosecutors may bring charges only to drop them, once it becomes clear how very difficult it is to secure a conviction for rape. ${ }^{5}$ Whether acquitted or never even tried, Star is likely to return to playing basketball, considered by most

3 In his initial police interview, Bryant claimed that he stopped having sex at the woman's request:

Detective Winters: When did she, when did you stop, what, what made you stop?

Bryant: Well, I asked her about the cuming in the face thing and she was like no, I don't know. ... I asked her if I could cum in her face and she was like no um, I thought she was cool, you know, I stopped. I stopped pumping.

Kobe Bryant Police Interview at 28 (cited in note 1). In her initial police interview, the woman told a very different story:

Accuser: That's when he continually had one hand around my neck and with his other hand pushed me over to the side of the two chairs, um, turned me around and bent me over and lifted up my skirt.

.

Winters: Are you telling him anything at this point, now?

Accuser: At that point I was just kinda scared and I said no a few times.

Winters: Okay. When you said no, were you bent over when you were saying no?

Accuser: Yeah, when he lifted up my skirt. I said no when he took off my underwear.

...

Winters: Did he hear you?

Accuser: Yes. He did.

Winters: How do you know he heard you?

Accuser: Because every time I said no, he tightened his hold around me.

In Her Own Words: Highlights of Transcript of Kobe Bryant's Accuser, NY Daily News (Oct 2, 2004), online at http://www.nydailynews.com/front/story/237881p-204166c.html (visited Feb 20, 2005).

4 Juries in cases involving sexual conduct seem to take the burden of proof very seriously. A juror interviewed after a well-publicized sexual harassment trial of an army officer said, "[I]t's not that we did not believe the women. It's that we had reasonable doubt." Martha Raddatz, McKinney Juror Speaks, National Public Radio, All Things Considered (Mar 19, 1998), audio online at http://www.npr.org/ramfiles/980319.atc.ram (visited Feb 20, 2005).

5 See Nick Madigan and Mindy Sink, End of Kobe Bryant Case Brings Out Strong Sentiment, NY Times A14 (Sept 3, 2004) (noting that although the Eagle County sheriff "still think[s] the charges were valid," the prosecution could not continue because the accuser was "reluctan[t] to proceed with a trial[] after setbacks for the prosecution and reports that she [the accuser] might have had other sex partners within days of her encounter with Mr. Bryant"). 
to be guilty of nothing worse than adultery. Supported by his loyal, forgiving wife, Star's reputation is refurbished and soon advertisements bearing his image return to television.'

The wrong of nonconsensual sex was likely not the only wrong perpetrated that night, however. Even if factually innocent of rape, Star may well be responsible for exacerbating the epidemic risks of HIV, pelvic inflammatory disease, various forms of genital cancers, nervous system damage, infertility, high blood pressure, thromboembolic disease, and something like posttraumatic stress disorder. ${ }^{8}$ Under current law, unless the prosecution can prove rape, these risks are routinely inflicted without any criminal sanction.'

This Article tries to fill that void in the criminal law by proposing a new crime of reckless sexual conduct, imposed for needlessly putting a sexual partner at such risk. The proposal is simple: a person would be guilty of reckless sexual conduct and subject to imprisonment for up to three months if, in a first-time sexual encounter with another specific person, he or she had sexual intercourse without using a condom. Consent to unprotected intercourse would be an affirmative defense, to be established by the defendant by a preponderance of the evidence. The prosecution would have to prove beyond a reasonable doubt that this was the first time that the defendant had sexual intercourse with the accuser and that no condom was used.

Because the concept of "first-time sexual encounter" is crucial to our analysis, let us pause to clearly define it. The term "first-time sexual encounter" refers to the first time that two particular people have sexual intercourse. It is distinguished from "subsequent sexual encounter," which refers to any subsequent sexual intercourse between the same two people. The term is not limited to the first time that an individual has sex. An individual who has a total of $\mathrm{N}$ sexual partners

6 Adultery is not a crime in most states and, with the exception of military prosecutions, is enforced virtually nowhere. See Martin Siegel, For Better or For Worse: Adultery, Crime and the Constitution, 30 J Fam L 45, 53 nn 54-59 (1991/1992).

7 See Kurt Badenhaussen, Kobe Bryant's Sponsorship Will Rebound, Forbes.com (Sept 3, 2004), online at http://www.forbes.com/business/2004/09/03/cz_kb_0903kobe.html (visited Feb 20 , 2005) (predicting that with the dismissal of the criminal charges and the then-impending civil settlement, Bryant's endorsement opportunities will return in a year or two).

8 If Star did not know whether the nineteen-year-old was infected with a sexually transmitted disease (STD), his choice to engage in unprotected sex increased the chance that both he and any other individuals with whom he would subsequently engage sexually (including his wife) would become infected. Indeed, the nineteen-year-old's accusation-even if false-may have reduced the risk that Star would spread a disease contracted in Colorado. The accusation may have prevented Star from engaging in unprotected sex subsequently with his wife (before being tested for STDs).

9 Only two states criminalize reckless endangerment with regard to HIV transmission, and the common law crime of reckless physical endangerment has been used only once to penalize someone who actually transferred another STD. See notes 127-33 and accompanying text. 
over the course of her life therefore engages in $\mathrm{N}$ first-time sexual encounters.

Unprotected first-time sexual encounters play a crucial role in exacerbating the prevalence of both sexually transmitted diseases (STDs) and acquaintance rape. While an increasing majority of people report and aspire to using condoms during casual sex, ${ }^{10}$ the unprotected residual of first-time sexual encounters may have a dramatic effect on the spread of infection. Unprotected first-time sexual encounters are also correlated with coercion. The lion's share of acquaintance rape (that is, nonstranger, nonrelative rape) occurs in unprotected first-time sexual encounters. ${ }^{11}$ Men who rape recklessly, by not finding the time or compassion to discern a partner's consent, rarely find time to use a condom.

Minimally regulating this small subset of sexuality can pay big dividends. Public policies designed to increase condom use will make progress with regard to both STD epidemics and acquaintance rape. Increased condom use in first-time sexual encounters will dramatically reduce the effective number of "nodes" in the network of potential infection for the simple reason that many sexual pairings do not result in subsequent sexual encounters. ${ }^{12}$ Increased condom use will also likely reduce the incidence of acquaintance rape. Giving men a new incentive to wear a condom in first-time sexual encounters should discourage the tragic lack of communication that often gives rise to the illusion of consent. ${ }^{13}$ The very act of stopping to put on a condom should increase deliberation and communication-the more delibera-

10 "Casual sex" has a number of different definitions. Some researchers define casual sex as a "one night stand." Others define it as intercourse on the first meeting. See, for example, Timothy Edgar and Mary Anne Fitzpatrick, Expectations for Sexual Interaction: A Cognitive Test of the Sequencing of Sexual Communication Behaviors, 5 Health Commun 239, 242 (1993) (defining a "casual sexual encounter" as "one in which two individuals meet for the first time and have sexual intercourse within a few hours"). Still others make the prior or later relationship between the two individuals irrelevant. See, for example, Jeffry A. Simpson and Steven W. Gangestad, Individual Differences in Sociosexuality: Evidence for Convergent and Discriminant Validity, 60 J Personality \& Soc Psychology 870, 870 (1991) (characterizing an "unrestricted sociosexual orientation" by three factors, two of which disregard either prior or later relationships: "sex without commitment" and "several different sexual partners in [a given] year").

11 See Part I.B.2.

12 See notes $42-46$ and accompanying text.

13 In the statement he released after his case was dropped, Bryant acknowledged that what he thought was consent had not been experienced that way by his alleged victim. See Kirk Johnson, As Accuser Balks, Prosecutors Drop Bryant Rape Case, NY Times A1 (Sept 2, 2004) (quoting Bryant's statement: "I recognize now that she did not and does not view this incident the same way I did.... I now understand how she feels that she did not consent to this encounter."). Bryant accepted what is now common wisdom among scholars in this field: miscommunication is often the primary cause of acquaintance rape. See text accompanying notes 84-87. 
tion and communication, the lesser the likelihood of acquaintance rape.

The crime of reckless sexual conduct will also be a powerful prosecutorial tool for the thousands of acquaintance rape cases that are simply not winnable under current law. It represents a way to partially overcome the "he said/she said" dilemma. A prosecutor who does not have enough objective evidence to go forward with a rape case could easily have enough objective evidence to prove reckless sexual conduct. Reasonable doubts can remain whether an alleged acquaintance rapist raped, but there is often no question that he engaged in an unprotected first-time sexual encounter. In such a case there could at least be a conviction, albeit for a much less serious offense. The threat of likely conviction can act as a significant deterrent to reckless conduct.

The message of our proposal is not necessarily to forgo one night stands, but rather to use a condom or communicate enough so that one can know one's partner is consenting to unprotected sex. The new crime of reckless sex would not replace current rape laws, and it would not immunize men who rape with condoms from prosecution under existing law. It also would not impose a punishment nearly as severe as rape. But, like laws prohibiting driving under the influence of alcohol, its very existence would send a clear message that society considers reckless sex both physically and emotionally damaging.

Our discussion is divided into four parts. Part I explains the dangers, both physical and emotional, of unprotected sex, and the particular dangers presented when a first-time sexual encounter between two people is unprotected. Part II describes the current laws regulating first-time sexual encounters and condom use. Part III then describes how the proposed statute would work and puts forward the affirmative case for its enactment. Finally, Part IV responds to two potential constitutional objections to the statute - whether the law's affirmative defense would unconstitutionally force defendants to prove a necessary element of the crime, and whether the law would unconstitutionally burden the rights of privacy and freedom of association.

\section{SEX Is DANGEROUS}

Sex is dangerous both physically and emotionally. While sexuality can be a core attribute of human expression, it can also be the occasion for infection and coercion. This Part details the dangers of disease and coerced sex and argues that a small subset of sexual activity-unprotected first-time sexual encounters between two peoplerepresents an unappreciated policy lever for addressing both STDs and acquaintance rape. 


\section{A. Physical Dangers of Unprotected Sex}

The exact number of people carrying STDs is impossible to determine because many STDs have no symptoms. One scholar has concluded that the number of undiagnosed cases of STDs probably exceeds the number of diagnosed cases, ${ }^{14}$ and over fifteen million new cases are diagnosed each year. ${ }^{15}$ One in six men aged fifteen to fortynine have genital herpes. ${ }^{16}$ Five million new cases of genital warts are diagnosed each year, ${ }^{17}$ and four million teenagers acquire an STD for the first time each year. ${ }^{18}$ Some estimate that 25 percent of sexually active teenagers carry an STD. ${ }^{19}$ Whether symptomatic or not, whether diagnosed or not, all carriers of STDs can spread disease unless they use condoms during intercourse. ${ }^{20}$ Virtually all STDs can be prevented by effective condom use."

There are six major sexually transmitted diseases in the United States. Three are bacterial: chlamydia, gonorrhea, and syphilis; and three are viral: HSV (genital herpes), HPV (genital warts), and HIV (which can lead to AIDS). ${ }^{2}$ Bacterial diseases are treatable with antibiotics, but if left untreated ${ }^{23}$ can cause sterility, destroy the nervous

14 See Dennis Fortenberry, Unveiling the Hidden Epidemic of Sexually Transmitted Diseases, 287 JAMA 768,768-69 (2002) (reporting that the number of undiagnosed and untreated cases of gonorrhea and chlamydia exceeded the number of cases presumed to have been treated in Baltimore, Maryland, during the same period).

15 Meg Meeker, Epidemic: How Sex Is Killing Our Kids 11 (LifeLine 2002).

16 Alan Guttmacher Institute, In Their Own Right: Addressing the Sexual and Reproductive Health Needs of American Men 52, 87 (2002) (citing unpublished tabulations of the Institute's 1988-1994 National Health and Nutrition Examination Surveys).

17 Id.

18 Cynthia Dailard, Family Planning Clinics and STD Services, 5 Guttmacher Rep Pub Policy 8, 8 (Aug 2002) (citing American Social Health Association estimates).

19 Meeker, Epidemic at 11 (cited in note 15).

20 Alan Guttmacher Institute, In Their Own Right at 41 (cited in note 16).

21 See, for example, Katherine M. Stone, Judy Timyan, and Elizabeth L. Thomas, Barrier Methods for the Prevention of Sexually Transmitted Diseases, in King K. Holmes, et al, eds, Sexually Transmitted Diseases 1307, 1307 (McGraw-Hill 3d ed 1998) (reporting that studies show that "condoms protect users and their partners against HIV and a wide variety of other STDS" and that many studies show condoms are "100 percent effective[]" against many STDs); Alan Guttmacher Institute, In Their Own Right at 55 (cited in note 16).

22 Alan Guttmacher Institute, In Their Own Right at 51-54 (cited in note 16).

23 It is not uncommon for bacterial infections, particularly in women, to go untreated because women are much more likely than men to be asymptomatic. See Gail Bolan, Anke A. Ehrhardt, and Judith N. Wasserheit, Gender Perspectives and STDs, in Holmes, et al, eds, Sexually Transmitted Diseases 117,122 (cited in note 21 ).

24 Untreated chlamydia can cause sterility in men and infertility, ectopic pregnancy, and chronic pelvic pain in women. Alan Guttmacher Institute, In Their Own Right at 53 (cited in note 16). 
system, ${ }^{25}$ and lead to spontaneous abortions, premature delivery, and birth defects. ${ }^{26}$ Viral diseases cannot be cured at all.

\section{Gender effects.}

The physical dangers of STDs are visited disproportionately on women. In any given episode of unprotected heterosexual intercourse with an infected partner, a woman is significantly more likely than a man to get an STD. In one single act of unprotected sex with an infected partner, a teenage girl has a 1 percent chance of contracting HIV, a 30 percent chance of contracting HSV (genital herpes), and a 50 percent chance of contracting gonorrhea. ${ }^{27}$ Male-to-female transmission of HIV during vaginal intercourse may be as much as twenty times more likely than female-to-male transmission. ${ }^{28} \mathrm{~A}$ recent study found that among discordant couples, where one partner is infected and the other is not, the annual risk of genital herpes transmission was 19 percent from men to women but only 5 percent from women to men. ${ }^{29}$ Women's increased susceptibility to some STDs is likely due to the fact that infected semen remains inside the female body for some time after intercourse, whereas the male is exposed to an infected female only during coitus. ${ }^{30}$ Moreover, it is worth noting that unwanted sex probably carries a greater risk of becoming infected with an STD. This is true not only because of the lower probability of condom use during unwanted sex." Unwanted sex also carries a greater risk of infection both because cervical mucus (which is not likely to be produced in a nonconsensual encounter) acts as a barrier to transmission ${ }^{32}$ and because the absence of mucus (not to mention potential force) is likely to lead to greater tearing and therefore greater chances for infection.

\footnotetext{
25 Untreated syphilis destroys the nervous system. Id.

26 These pregnancy-related problems are often symptoms of gonorrhea. Id

27 Alan Guttmacher Institute, Teen Sex and Pregnancy (Sept 1999), online at http://www.agi-usa.org/pubs/fb_teen_sex.html (visited Feb 20, 2005).

28 See Bolan, Ehrhardt, and Wasserheit, Gender Perspectives and STDs at 121 (cited in note 23). See also Roy M. Anderson and Robert M. May, Infectious Diseases of Humans: Dynamics and Control 230 (Oxford 1991) ("[T]he net female-to-male transmission probability [for gonorrhea infection] may be around 0.5 , and the male-to-female around 0.9 , per encounter. These detailed values are of less significance in the models than is their ratio, namely 1:2 (female to male versus male-to-female; gonorrhea does not obey Title IX)."). 23).

29 Bolan, Ehrhardt, and Wasserheit, Gender Perspectives and STDs at 121 (cited in note

30 Id.

31 See notes $90-93$ and accompanying text.

32 Bolan, Ehrhardt, and Wasserheit, Gender Perspectives and STDs at 120 (cited in note 23).
} 
If infected, women are more likely than men to develop serious medical complications. AIDS affects both sexes equally, but most other STDs do not. ${ }^{33}$ Studies indicate that if not properly treated, 10 to 45 percent of women infected with gonorrhea and 10 to 30 percent of women infected with chlamydia develop pelvic inflammatory disease, an upper genital tract infection. ${ }^{34}$ Men are not nearly as susceptible to this kind of infection. ${ }^{35}$ Of women with pelvic inflammatory disease, one in five will become infertile; one in ten will have an ectopic pregnancy (in which the fetus implants on the outside of the uterus), which is the leading cause of first-trimester deaths among American women in the United States. ${ }^{36}$ Certain kinds of genital warts are linked to the development of genital cancers in both sexes, but the genital cancers that women get-cervical, vulvar, vaginal, and anal-are fairly common, whereas penile cancer, the only cancer linked to genital warts in heterosexual men, is rare. ${ }^{37}$

Furthermore, women infected with an STD are particularly vulnerable to serious pregnancy complications, including spontaneous abortions, stillbirths, premature rupture of membranes, and preterm delivery. ${ }^{38}$ The fetuses these women carry are susceptible to central nervous system damage, eye infections (which can lead to blindness), and pneumonia (which can lead to chronic lung disease). ${ }^{39}$ Thus, unprotected sex leaves women at greater risk of contracting an STD, and if a woman contracts an STD, she incurs a substantial risk of physical injuries that men simply do not encounter.

\section{Epidemiological effects.}

Unprotected sex with an STD carrier is dangerous business. One's likelihood of contracting or giving an STD is linked to one's number of sexual partners. ${ }^{40}$ In particular, people who engage in un-

33 Id at 123 ("HIV is more symmetric in the gender distribution of complications. However, efficiency of transmission is greater from men to women than women to men and thus, the potential for gender differences in HIV prevalence in some populations is very real.").

34 Id.

35 Id at 121 (referring to the possibility that the cervix is more easily infected than the urethra).

36 Id at 123.

37 Id. However, gay and bisexual men are also susceptible to heightened rates of anal cancer caused by genital warts. See Public Health Seattle \& King County, Anal Cancer Among the Gay and Bisexual Men, online at www.metrokc.gov/health/glbt/analcancer.htm (visited Feb 20,2005).

38 Bolan, Ehrhardt, and Wasserheit, Gender Perspectives and STDs at 123 (cited in note 23).

39 Id.

40 See Roy M. Anderson, Transmission Dynamics of Sexually Transmitted Infections, in Holmes, et al, eds, Sexually Transmitted Diseases 25, 28 (cited in note 21) (observing that the "sex 
protected sex with two or more partners in a short period of time play a central role in the spread of infection. ${ }^{41}$

First-time sexual encounters are particularly important to the epidemiological force of an STD. The average person in the United States has sex with seven to nine partners over the course of his or her life, but many of these encounters are "one night stands" (that is, first-time sexual encounters that are never followed by subsequent sexual encounters with this partner). Promoting condom use just in first-time sexual encounters can have a dramatic effect on the rate of STD infection because so many sexual encounters are one night stands.

What proportion of sexual relationships is comprised of just one night stands? A national survey of one thousand Americans between the ages of eighteen and sixty-five found that 9 percent of respondents reported having had at least eleven one night stands (another 26 percent reported having between two and ten). ${ }^{43}$ A 1991 survey of Texas college students found that 24 percent of those sampled reported having two or more one night stands in just the last year."

To get a more particularized answer to that question, we analyzed the National Health and Social Life Survey database that was collected in 1992 by the National Opinion Research Center. ${ }^{45}$ Individuals reported that they had sex just one time with 46.2 percent of all sexual

partner change rate occupies a central position in determining the generation of secondary cases").

41 Id at 31-32. Of those people infected with an STD, a higher proportion of women than men are only "receivers," that is, they did not engage in unprotected sex with anyone other than a long-standing partner. They "received" an STD only because of the risky behavior of their partners. See Sevgi O. Aral and King K. Holmes, Social and Behavioral Determinants of the Epidemiology of STDs: Industrialized and Developing Countries, in Holmes, et al, eds, Sexually Transmitted Diseases 39,59 (cited in note 21). Unlike many of the gendered effects of STDs, this medical conclusion may stem more from social facts regarding gendered sexual behavior than from physiology or biology. Nonetheless, it suggests that not only are women more vulnerable to acquiring and suffering from STDs, they are less culpable in transmitting them.

42 Tom W. Smith, Adult Sexual Behavior in 1989: Number of Partners, Frequency of Intercourse and Risk of AIDS, 23 Fam Planning Perspectives 102, 103 table 1 (1991) (showing that the mean number of sexual partners since age eighteen is 7.15 when considering all demographic characteristics).

43 See Adam Marcus, America's Fleeting Passions: One-Night Stands Are Not That Rare, Survey Says, Health Scout Rep (Sept 18, 2002), online at http://knbc-tvhealth.ip2m.com/ index.cfm?pt=itemDetail\&item_id=74710 (visited Feb 20, 2005) (reporting the results of a national survey).

44 Betty A. Harris, Sexuality Standards, Sexual Attitudes and Sexual Behavior at 6, online at http://dataguru.org/love/sexstd/index.asp (visited Feb 20, 2005).

45 For the data, see The National Health and Social Life Survey ("The Sex Survey"): Summary, online at http://cloud9.norc.uchicago.edu/faqs/sex.htm (visited Feb 20, 2005). For a STATA version of the data together with our do and log files, see Ian Ayres, Downloadable Publications, online at http://islandia.law.yale.edu/ayers/ (visited Feb 20, 2005). 
partners that they had over their adult lives. ${ }^{46}$ This means that if society could somehow induce people to use condoms in all of their firsttime sexual encounters (even if we left unchanged the amount of sexuality and the degree of condom use in subsequent sexual encounters), we would suddenly eliminate roughly half the possible nodes of contact for spreading disease. We might so dramatically reduce the mean number of connections in the population as to render infections unsustainable over time.

The idea of intervening to promote condom use in casual sexual encounters has been the cornerstone behind Thailand's recent 100 percent condom use policy, pursuant to which the state has provided free condoms in brothels. ${ }^{47}$ It is also the basis of the "ABC" approach-abstinence, be faithful, condom use-to AIDS prevention." The "be faithful" component is often shorthand for a strategy of partnership reduction. ${ }^{49}$ Enhanced condom use in casual or short-term sexual relationships can have the same effect without reducing the actual number of partners. Because effective condom use largely eliminates the probability of infection for many types of STDs, it is as if many of these one-time sexual encounters did not exist from an epidemiological perspective. Changing behavior in just first-time sexual encounters is accordingly the kind of target policy that might pay huge dividends in disintegrating the network of infection.

46 The number is based on an analysis of 560 respondents who reported having a total of 5,045 sexual partners during the course of their adult lives (after age eighteen), 2,330 of whom were partners with whom they had sex only one time. The specific question asked for the number of partners with whom they had "had sex." See Edward O. Laumann, et al, National Health and Social Life Survey, 1992: United States, 6647 ICPSR $\$ 4$ at 569 (Inter-University Consortium for Political and Social Research 1995), online at http://www.icpsr.umich.edu/cgi-bin/ bob/file?comp=none \&study=6647\&ds=1\&dsfmt=LREC\&filetype=CBLT (visited Feb 20, 2005) (defining "sex" as "any mutually voluntary activity with another person that involves genital contact and sexual excitement or arousal"). See also id $\$ 6$ at 594-603 (asking about all sexual partners since age eighteen). A separate set of 1,627 respondents reported having a total of 4,324 sexual partners before they were nineteen years old, 1,506 (or 35.6 percent) of whom were partners with whom they had sex only one time. See Ayres, Downloadable Publications (cited in note 45). Our analysis did not control for the heterogeneity in ages of respondents. Some respondents would have more sexual partners in the future as they age, and this might affect the proportion of partners who are one night stands.

47 See Nicholas Ford and Suporn Koetsawang, A Pragmatic Intervention to Promote Condom Use by Female Sex Workers in Thailand, 77 Bull World Health Org 888 (1999).

48 See John D. Shelton, et al, Partner Reduction Is Crucial for Balanced "ABC" Approach to HIV Prevention, 328 Brit Med J 891, 891 (2004) (stressing the importance of behavior change programs).

49 Id. See also Helen Epstein, The Fidelity Fix, NY Times Mag 54 (June 13, 2004) ("As experts come to understand more about the African AIDS epidemic, it seems clear that regular sexual contact with more than one person is the key human behavior that enables the rapid spread of H.I.V."). 
The benefits of promoting condom use in first-time sexual encounters become all the more important when we analyze how the heterogeneity or variance in the number of partners impacts the force of an epidemic. It is immediately intuitive that an STD is more likely to spread when the average person in a population has a larger number of sexual partners, but the variance in number of sexual partners in a population is also positively related to the expected replication rate of an STD. ${ }^{30}$ Epidemiologists have modeled the force of an epidemic in populations with heterogeneous sexual frequency:

$$
R_{0}=\rho_{0}\left(\mu+\frac{\sigma^{2}}{\mu}\right)
$$

where $\rho_{0}$ is the product of the transmission probability per partner (sometimes referred to as the "efficiency" of transmission) and the average duration of the disease, $\mu$ is the mean number of partners per unit time, and $\sigma^{2}$ is the variance of the number of partners. ${ }^{5} R_{0}$ measures the "infector number" (sometimes referred to as "reproductive rate" or "threshold parameter") - the average number of secondary infections produced by a single index case in a population of susceptible persons. "The disease rate is stable (or "endemic") when the infector number $\left(R_{0}\right)$ equals one, epidemic when greater than one, and eventually zero (the disease will die out over time) when less than one. $^{53}$

50 The "variance" in number of sexual partners refers to the size of the numerical difference between the person (or people) who have the fewest sexual partners and the person (or people) who have the most. The "replication rate" of a disease refers to the extent to which the disease spreads from one person to another.

51 Anderson and May, Infectious Diseases of Humans at 233 (cited in note 28). See also Fredrik Liljeros, Christofer R. Edling, and Luis A. Nunes Amaral, Sexual Networks: Implications for the Transmission of Sexually Transmitted Infections, 5 Microbes \& Infection 189, 191 (2003).

52 See James C. Thomas and Myra J. Tucker, The Development and Use of the Concept of a Sexually Transmitted Disease Core, 174 J Infectious Diseases 134 (Supp 2, 1996).

53 This formula assumes a uniform probability that a sexual relationship between an infected and an uninfected person will lead to the uninfected person becoming infected. But the probability that an infection will be transmitted will be influenced in part by the number of sexual encounters that a particular pair has. Securing condom use in first-time sexual encounters will effectively eliminate a large proportion of nodes from the sexual network, but it is the nodes that may have lower probabilities of infection (because these sexual encounters tend to be one night stands). To more accurately estimate the impact of increased condom use in first-time sexual encounters, a formula analogous to Equation 1 would have to take account of both heterogeneity in the number of partners and also in the number of sexual encounters per partner. An important article by Sally Blower and Carl Boe provides some empirical support for our contention that enhancing condom use in just first-time sexual encounters would have a beneficial impact in reducing the spread of STDs. Sally M. Blower and Carl Boe, Sex Acts, Sex Partners and Sex Budgets: Implications for Risk Factor Analysis and Estimation of HIV Transmission 
From the foregoing equation, it is clear that (for a given fixed average number of partners) the larger the variance, the larger the epidemiological force of the disease. This means that populations with a larger variance in the number of partners will produce self-sustaining epidemics with less infectious STDs (that is, with smaller $\rho_{0}$ ). The intuition for the positive impact of variance is that populations with low means but high variances in the number of sexual partners are likely to exhibit large connected networks of sexual nodes. The few members of the population with many sexual partners are likely to form connections with the rest of the population who have few other sexual partners. Randomly infecting a node in a high-variance network is therefore likely to yield a large epidemic. ${ }^{54}$

The importance of variance to the epidemiological force of infection matters because human sexuality often exhibits extremely high variance in the number of sexual partners. Indeed, as an empirical matter, the distribution of the number of sexual partners is highly skewed to the right. The great majority of people have had only one or zero sexual partners in the last year (and only a handful during the course of their lives), but a few people report dozens or even hundreds of partners. As one researcher put it, "Your partners have more partners than you have yourself!" "s5 Partnership distributions have such a heavy tail that some researchers have found evidence suggesting that human sexuality might be an example of a scale-free network with an infinite variance. ${ }^{36}$ If human sexuality is a scale-free network,

Probabilities, 6 J Acquired Immune Deficiency Syndromes 1347 (1993). Even after expressly taking into account the heterogeneity in the number of sex acts per partnership, they find that

even though the individuals with high numbers of partners are only a small proportion of the sample ( $17 \%$ of males and $7 \%$ of females), they are contributing disproportionately to the spread of the HIV epidemic because they are involved in the formation of a high proportion of the partnerships ( $39 \%$ of the male partnerships and $21 \%$ of the female partnerships). Id at 1352.

54 See Robert M. May and Alun L. Lloyd, Infection Dynamics on Scale-Free Networks, 64 Physical Rev E 4 (Nov 2001) ("An important finding that emerges from our analysis is the crucial role played by the most highly connected nodes in spreading infection and ... in maintaining infection.").

55 Fredrik Liljeros, Sexual Networks in Contemporary Western Societies 19, presented at the Second International Conference on Frontier Science (Sept 2003), online at http:www.pv.infn.it/ frontier/2003/talks/Liljeros.ppt (visited Feb 20, 2005).

56 A scale-free network is one where the distribution of connectivity is extremely uneven. In networks where the degree of connectivity follows a power law, the probability $\mathbf{P}(\mathrm{k})$ that a node in the network connects with $\mathrm{k}$ other nodes is proportional to $\mathrm{k}^{\mathrm{v}}$. See Albert-Lászlo Barabási and Reka Albert, Emergence of Scaling in Random Networks, Sci 509, 510 (Oct 15, 1999) (proposing a model to account for stationary scale-free distributions). Scale-free distributions can exhibit infinite variance because the tails of the distribution are sufficiently fat that squaring the deviations from the mean is exponentially greater than the decline in probability mass. See Anne Schneeberger, et al, Scale-Free Networks and Sexually Transmitted Diseases: A Description of Observed Patterns of Sexual Contacts in Britain and Zimbabwe, 31 Sexually 
policies aimed at reducing the number of unprotected sexual encounters are likely to be highly effective means of reducing infection:

Another property of scale-free networks is that despite their high susceptibility they are very sensitive to strategic removal of nodes. This turns out to be of importance for the prevention of the spread of [sexually transmitted infections] because if only a few very active persons are removed (or change their behavior), the network very soon falls apart in separated components, thus preventing the emergence of epidemics."

Even if the distribution of sexual partners is not infinite, what is important for policy is that the extreme right skew of the distribution makes the variance so large that the reproductive number for many STDs will exceed the crucial threshold number of one-causing the size of the infection to increase over time-almost regardless of the mean number of sexual partners or the degree of disease infectiousness.

The average sexual behavior of most populations is probably not sufficient to sustain either an epidemic or an endemic STD infection. ${ }^{58}$ For example, if everyone had exactly eight sexual partners during the course of his or her lifetime (so that the variance in the number of partners was zero) most STDs would cease to exist. Rather, the driving factor of most STDs is clearly the tail of the distribution. ${ }^{59}$ This minority of people who have many sexual partners-sometimes referred to as "the core"-crucially determines the force of the infection. ${ }^{60}$ Our analysis of the National Health and Social Life Survey database confirms the tremendous concentration of sexuality in the tail of the distribution. We found that the 10 percent of most sexually ac-

Transmitted Diseases 380 (2004) (concluding that the number of reported sexual partners can be described through the scale-free network approach).

57 Liljeros, Edling, and Amaral, 5 Microbes \& Infection at 194 (cited in note 51) (emphasis added). See also Schneeberger, et al, 31 Sexually Transmitted Diseases at 382 (cited in note 56) ("[C]ontrol programs are best targeted toward the most sexually active people.").

58 See James Holland Jones and Mark S. Handcock, An Assessment of Preferential Attachment as a Mechanism for Human Sexual Network Formation, 270 Proceedings Royal Socy London Series B Biological Sci 1123 (2003) (noting that the existence of STD epidemics is a puzzle "given the relatively small number of sexual contacts people have").

59 See Hein Stigum, W. Falck, and P. Magnus, The Core Group Revisited: The Effect of Partner Mixing and Migration on the Spread of Gonorrhea, Chlamydia and HIV, 120 Mathematical Biosciences 1,10 (1994).

60 Id. If a member of the core is more likely to have sex with another member of the core than with a person who is not a member of the core, then the impact of variance on the force of the infection will be less than suggested by Equation 1 . See id at 19-20. 
tive people reported having 75.4 percent of the total number of sexual partners.

This tremendous skew underscores the importance of using firsttime sexual encounters as a policy lever to regulate the tail of the distribution. It is almost certainly true that the further one goes into the right-hand tail of the number-of-partners distribution, the larger the probability that a first-time sexual encounter is a one-time sexual encounter. Indeed, Figure 1 estimates just this relationship based again on the National Health and Social Life Survey database.

FIGURE 1

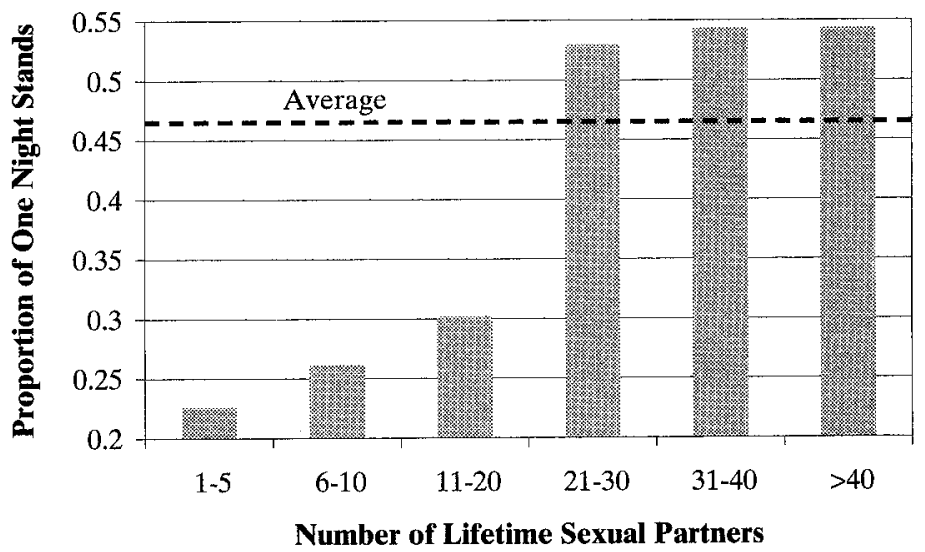

Figure 1 shows a dramatic increase in the probability of one night stands for respondents who are more sexually active. While the probability that a random first-time sexual encounter will end up being a one night stand is 46.2 percent, we see that people with a smaller number of lifetime partners report a lower proportion (22.4 percent for people who had between one and five partners) and people with a larger number of lifetime partners report a higher proportion (52.8 percent for people who had between twenty-one and thirty partners). That is, the more sexual contacts one has over a lifetime, the greater

61 This percentage is calculated on the basis of partners that 560 respondents reported having over their adult (over age eighteen) lifetimes. The top decile of 1,627 respondents who were asked about their sexual partners before they turned nineteen had 67.1 percent of the total number of reported sexual partners. This calculation, like the other calculations based on this data, see note 66 and accompanying text, take the individual self-reported assessments of sexuality to be true. In other contexts, it would be natural to question or exclude outlier observations, but in trying to estimate the degree of skew, STD researchers routinely rely on the accuracy of outlier reporting. See, for example, Jones and Handcock, 270 Proceedings Royal Socy London Series B Biological Sci 1123 (cited in note 58). 
the proportion of one's sexual contacts that are likely to be one night stands.

Figure 1 suggests that regulating one night stands is a powerful way to target the right-hand tail of the distribution. Promoting condom use for one night stands can reduce the effective size of the righthand tail of the distribution, and it is this tail that is so crucial to the reproductive force of the infections. STD scholars have long recognized that this right-hand tail is responsible for the force of the epidemics and needs to be targeted. ${ }^{63}$ But with the important exception of interventions directed toward prostitutes, most of the efforts have been untargeted programs of general education. Figure 1 shows that promoting condom use in first-time sexual encounters is likely not just to reduce the mean number of nodes where unprotected sex occurs, but also to have a disproportionate impact on the right-hand tail, and therefore likely to reduce significantly the variance in the number of unprotected sexual encounters of the distribution. ${ }^{64}$

Table 1 estimates just these impacts (using the National Health and Social Life Survey database) by calculating the mean and variance on the number of adult lifetime partners-both including and excluding partners with whom a respondent reported having sex just one time.

62 Blower and Boe similarly find, analyzing the San Francisco Home Health Study, that heterosexual males who reported having one sexual partner in the last year had a median of forty sexual acts with that partner, while heterosexual males who reported having ten sexual partners in the last year had a median of one sexual act with each partner. Blower and Boe, $6 \mathrm{~J}$ Acquired Immune Deficiency Syndromes at 1350 table 2 (cited in note 53). "[1]ndividuals with higher numbers of partners have fewer acts during a partnership than individuals with lower numbers of partners." Id at 1351.

63 See, for example, Anderson and May, Infectious Diseases of Humans at 230 (cited in note 28) ("If the core individuals could all be identified and kept free of gonorrhoea (by persistent surveillance and treatment, or by the use of an as-yet hypothetical vaccine), the disease would die out, because its basic reproductive rate in the remaining non-core population is less than unity.").

64 Our argument interestingly parallels that of Neal Katyal with regard to the sale of illicit drugs. See Neal Kumar Katyal, Deterrence's Difficulty, 95 Mich L Rev 2385 (1997). Katyal argued that drug sales to first-time users were more socially deleterious, because of addiction, than drug sales to established addicts - and that therefore it was appropriate to single out first-time encounter drug sales (that is, the first encounter between a seller and buyer) for harsher sanction. See id at 2440 . In this Article, we are arguing that unprotected first-time sexual encounters (because of the prevalence of one night stands) are more socially deleterious than unprotected subsequent sexual encounters - and that therefore it is appropriate to single out first-time sexual encounters for harsher sanction. 
TABLE 1

Impact of Excluding One Night Stands on Mean and Variance of Distribution of Number of Lifetime Sexual Partners

\begin{tabular}{|l|c|c|c|c|c|c|c|}
\hline & \multicolumn{2}{|c|}{$\begin{array}{c}\text { Including } \\
\text { One Night } \\
\text { Stands }\end{array}$} & \multicolumn{2}{|c|}{$\begin{array}{c}\text { Excluding } \\
\text { One Night } \\
\text { Stands }\end{array}$} & \multicolumn{2}{|c|}{$\begin{array}{c}\text { Percent } \\
\text { Reduction }\end{array}$} & $\begin{array}{c}\text { Percent } \\
\text { Increase in } \\
\text { Minimally } \\
\text { Sustaining } \rho\end{array}$ \\
\hline & Mean & Var. & Mean & Var. & Mean & Var. & \\
\hline $\begin{array}{l}\text { Full Adult } \\
\text { Sample } \\
\text { (N=560) }\end{array}$ & 9.01 & 45.81 & 4.20 & 15.85 & $53.3 \%$ & $65.4 \%$ & $76.7 \%$ \\
\hline $\begin{array}{l}\text { Heterosexual } \\
\text { Male } \\
(\mathrm{N}=271)\end{array}$ & 10.32 & 33.13 & 5.34 & 13.22 & $48.2 \%$ & $60.1 \%$ & $73.1 \%$ \\
\hline $\begin{array}{l}\text { Heterosexual } \\
\text { Female } \\
\text { (N=253) }\end{array}$ & 3.43 & 13.15 & 1.96 & 3.06 & $42.9 \%$ & $76.7 \%$ & $106.3 \%$ \\
\hline $\begin{array}{l}\text { Homosexual } \\
\text { Male (N =20) }\end{array}$ & 67.10 & 199.52 & 18.95 & 66.32 & $71.8 \%$ & $66.8 \%$ & $212.1 \%$ \\
\hline $\begin{array}{l}\text { Youth Sample } \\
\text { (N =1,627) }\end{array}$ & 2.60 & 6.59 & 1.68 & 4.27 & $35.6 \%$ & $35.2 \%$ & $21.6 \%$ \\
\hline
\end{tabular}

For the sample, we found in the first row of Table 1 that the mean number of lifetime sexual partners was 9.01 with a variance of 45.81 . But when we excluded partners with whom the respondent reported having sex only once, the mean and variance fell to 4.2 and 15.85 , respectively. Given the rising proportion of one night stands in the tail of the distribution, it should not be surprising that the variance fell by a greater percentage (65.4 percent) than the mean (53.3 percent).

The remaining rows in Table 1 report similar analyses for different samples or subsamples. The subsamples of heterosexual men, heterosexual women, and homosexual men follow the same basic pattern-exhibiting substantial drops in both the mean and the variance of the distribution once one night stands are excluded. ${ }^{\text {is }}$ The large disparity in the mean number of sexual partners reported by heterosexual males and females (10.32 versus 3.43, respectively) often raises a concern about systematic over- and/or underreporting of sexual contacts. $^{66}$

65 Homosexual women were excluded from the analysis because only four women reported being lesbian, all four of whom reported engaging in no one night stands.

66 In a world where all sexual contacts were heterosexual, the mean number of male and female contacts would have to be identical. Besides misreporting by men and/or women, the literature has suggested that at least part of the disparity might be due to the failure of surveys to include female prostitutes who may be responsible for an elevated male average. See generally 
The reductions for homosexual men are particularly noteworthy. The mean and variance of lifetime partners for homosexual men are more than five times greater than for any other orientation. But again the exclusion of one night stands dramatically reduces the mean by 71.8 percent and the variance by 66.8 percent. The final row undertakes a similar analysis for the 1,627 respondents in the youth sample. As before, the exclusion of one night stands reduces the mean and variance of the distribution - and hence the force of STD epidemicsbut the size of the reductions is more modest (on the order of onethird).

The reductions in the effective means and variances of the partnership distribution both work to reduce the epidemiological force of STDs. This can be seen directly in Equation 1 (by the positive derivative of the reproductive rate both with regard to the mean and the variance) ${ }^{67}$ Indeed, if we remember that an epidemic will be sustainable only if the reproductive rate $\left(R_{0}\right)$ is greater than or equal to one, it is possible to derive the minimum $\rho$ that will sustain an STD epidemic. ${ }^{68}$ Increase in this minimum $\rho$ is good because it means that any STD with a lower $\rho$ will not be sustainable. The last column of Table 1 shows how the reductions in mean and variance (which would be wrought by dropping one night stands from the distribution) would impact the minimum $\rho$ that will sustain an STD epidemic. The table shows that this minimum threshold increases by more than 75 percent for the sample concerning adult sexual partners and by more than 200 percent for the subsample of homosexual males.

The reductions reported in Table 1 represent a heuristic upper bound on the potential health benefits of promoting condom use in first-time sexual encounters. Because condoms substantially reduce the risk of many STD infections, achieving 100 percent condom use in first-time sexual encounters would effectively remove one night stands from the effective distribution of sexual contact. But these im-

Devon Brewer, et al, Prostitution and the Sex Discrepancy in Reported Number of Sexual Partners, 97 Proceedings Natl Acad Sci 12385 (2000).

67 The derivative of the reproductive rate with regard to mean is only positive for a particular range of values. Holding the variance and the efficiency of the disease constant, increases in the mean can actually reduce the force of an infection if the mean number of partners is less than the standard deviation of partners: $\mathrm{d} R_{0} / \mathrm{d} \mu>0$ if $\mu<\sigma$.

68 The equation again is:

$$
R_{0}=\rho_{0}\left(\mu+\frac{\sigma^{2}}{\mu}\right)
$$

$\rho$ is a measure of how efficiently a disease is transmitted to a partner multiplied by the average duration of an infection. But as emphasized above, see note 53 , this equation ignores the heterogeneity of sexual acts across partnerships. The estimates of the impact on the reproductive rate should only be taken as a heuristic. 
pacts overstate the potential benefits for two important reasonsmany people already use condoms in first-time sexual encounters, and policies aimed at promoting condom use in first-time sexual encounters are unlikely to be fully effective. To gauge the impact of policies that are only partially effective at achieving condom use in firsttime sexual encounters, Table 2 recalculates the impact on the distribution for policies that remove for epidemiological purposes just a portion of one night stands.

TABLE 2

Impact of Excluding Some Proportion of One Night Stands on Mean and Variance of Distribution of Number of Lifetime Sexual Partners

\begin{tabular}{|l|c|c|c|c|c|c|c|}
\hline & \multicolumn{2}{|c|}{$\begin{array}{c}\text { Including } \\
\text { One Night } \\
\text { Stands }\end{array}$} & $\begin{array}{c}\text { Excluding Some } \\
\text { Proportion of } \\
\text { One Night } \\
\text { Stands }\end{array}$ & \multicolumn{2}{|c|}{$\begin{array}{c}\text { Percent } \\
\text { Reduction }\end{array}$} & $\begin{array}{c}\text { Percent } \\
\text { Increase in } \\
\text { Minimally } \\
\text { Sustaining } \rho\end{array}$ \\
\hline & Mean & Var. & Mean & Var. & Mean & Var. & \\
\hline $\begin{array}{l}\text { Excluding } \\
100 \%\end{array}$ & 9.01 & 45.81 & 4.20 & 15.85 & $53.3 \%$ & $65.4 \%$ & $76.7 \%$ \\
\hline $\begin{array}{l}\text { Excluding } \\
50 \%\end{array}$ & 9.01 & 45.81 & 6.31 & 29.85 & $29.9 \%$ & $34.8 \%$ & $27.6 \%$ \\
\hline $\begin{array}{l}\text { Excluding } \\
20 \%\end{array}$ & 9.01 & 45.81 & 7.58 & 38.82 & $15.9 \%$ & $15.3 \%$ & $11.0 \%$ \\
\hline $\begin{array}{l}\text { Excluding } \\
10 \%\end{array}$ & 9.01 & 45.81 & 8.00 & 41.85 & $11.2 \%$ & $8.7 \%$ & $6.5 \%$ \\
\hline
\end{tabular}

Table 2 compares the impact for the adult sample of excluding various proportions of reported one night stands from the overall distribution. For comparison, the first row repeats the first row of Table 1. Succeeding rows then show the impact if every individual excluded a certain proportion of his or her one night stands. The idea here is to heuristically estimate what would happen if a policy were effective at inducing people to use condoms in, say, 20 percent of the sexual encounters where condoms are currently not being used. The table shows smaller reductions in means and variances and correspondingly smaller increases in the minimally sustaining threshold for $\rho^{70}$

Because so many sexual encounters are one night stands, promoting condom use in first-time sexual encounters will generally reduce the mean number of unprotected sexual pairings or nodes of sexual

\footnotetext{
69 See notes 189-91 and accompanying text.

70 This estimation crucially assumes that a policy would have an equal impact on all people - regardless of their level of sexuality.
} 
contact. Because the prevalence of one night stands increases substantially for the subset of the population with many sexual partners, promoting condom use in first-time sexual encounters will produce a particularly large impact in reducing the variance in the distributions of the number of unprotected sexual partners. The results of Figure 1 and Table 1 provide dramatic evidence of the potential benefits of regulating first-time sexual encounters. We can now see that it is an important lever for indirectly regulating the right-hand tail of the distribution.

\section{B. Emotional Dangers of Nonconsensual Sex}

The dangers of sex are not limited to disease. Sex is emotionally dangerous as well because, in addition to their physical qualities, many sexual acts have significant emotional content. "Some scholars and probably most people simply accept that there is emotional vulnerability in sex. ${ }^{n}$ Others, though, have tried to minimize the emotional content of sex, either for pedagogical or policy reasons. ${ }^{73}$ There are advantages to minimizing the emotional content of sex because if sex is not experienced or idealized as a deeply emotional encounter, then one stands to lose less emotionally if the encounter does not go well. Forced, coerced, and simply unwanted sex would likely be less injurious if what was being forced, coerced, and taken was not seen or experienced as anything more than a physical act.

Critiques of the attempts to minimize the emotional content of sex suggest, however, that to take the emotional content out of sex is to rob sex, and indeed humanity, of critical, self-constitutive meaning. As Martha Nussbaum points out, the excruciating toll that the emotional content of sexual desire takes on people's souls is a core literary

71 The physical dangers of STDs bring their own emotional harm, but here we focus on the emotional dangers of nonconsensual sex even when no STD is transmitted.

72 See, for example, Stephen J. Schulhofer, Unwanted Sex: The Culture of Intimidation and the Failure of the Law 100, 117 (Harvard 1998) (referring to the "emotional vulnerability" and "emotional consequences" inherent in sexual encounters); John O.G. Billy, et al, Effects of Sexual Activity on Adolescent Social and Psychological Development, 51 Soc Psychology Q 190, 209 (1988) (finding that "having sex [in adolescence] gives rise to" emotional and psychological consequences, namely "more sexually permissive attitudes and expectations, which in turn may affect such outcomes as value on academic achievement, deviance proneness, religiosity, and church attendance"). See also note 88 .

73 See, for example, Linda R. Hirshman and Jane E. Larson, Hard Bargains: The Politics of Sex (Oxford 1998) (endorsing a "bargaining approach" to sexual regulation wherein women who bargain in sexual exchanges can be protected by laws that govern the marketplace and labor markets, instead of being abandoned because of a resistance to the adjudication of emotional, personal issues); Richard A. Posner, Sex and Reason 111-45 (Harvard 1992) (encouraging an understanding of sex as a rational act pursuant to bioeconomic theory); Donald A. Dripps, $B e$ yond Rape: An Essay on the Difference Between the Presence of Force and the Absence of Consent, 92 Colum L Rev 1780 (1992) (endorsing a commodification view of sex wherein the crime of rape involves the theft of that commodity). 
tradition. ${ }^{74}$ This tradition teaches that risking emotional loss is necessary if we are to "expose[] [ourselves] to real joy." Robin West suggests that when we think of our sexual experiences as physical exchanges, experiences that do not necessarily involve soul or self, "we justifiably think of ourselves as being in some way deadened in the process." "Ideally-and it may be an ideal worth holding on to-the 'self' is given with the giving of sex." Sex is emotionally dangerous because if one experiences it as an emotional act, one runs the risk of profound loss and rejection.

The emotional injury associated with sex is not limited to feelings of loss and rejection, however. The harm done by nonconsensual sex is often described as closer to fatal. When one is raped, sex is taken, not given. Rape in a world in which the emotional content of sex is minimized is a violent physical act. ${ }^{78}$ Rape in a world in which the emotional content of sex is idealized is a violent emotional act as well. One's ability to make oneself vulnerable in a manner that enables the self-constitutive, joyful giving of self in sex becomes compromised after rape because sex has been experienced not only as physically violent, but as devoid of compassion and self. It is an experience not of being rejected, but of being invaded and overcome. That is why the literary tradition teaches us that rape is akin to spiritual murder. ${ }^{79}$ Once one has been raped, it becomes very difficult to make love.

74 Martha Nussbaum, "Only Grey Matter"? Richard Posner's Cost-Benefit Analysis of Sex, 59 U Chi L Rev 1689, 1724-26 (1992).

75 Id at 1721.

76 Robin L. West, Legitimating the Illegitimate: A Comment on Beyond Rape, 93 Colum L Rev 1442,1451 (1993) (criticizing the view that sex is a commodity and that rape is theft).

77 Id.

78 Even if there is no struggle, "unwanted sexual penetration involves unwanted force, and unwanted force is violent -it is physically painful, sometimes resulting in internal tearing and often leaving scars." Id at 1448.

79 Consider these two passages describing the feelings of women being raped:

The screams tried to break through her corneas out into the air, but the tough rubbery flesh sent them vibrating back into her brain, first shaking lifeless the cells that nurtured her memory. Then the cells went that constrained her powers of taste and smell. The last that were screamed to death were those that supplied her with the ability to love-or hate.

Gloria Naylor, The Women of Brewster Place 170-71 (Viking 1982);

Charlotte felt "Charlotte" pass from her, she felt herself pass over into the noise.... [N]ot a person, not a girl, not even a body rigid with terror: but noise, shouts, blows. . . Pain or spasms of pleasure ... what did these matter? ... Love, hate, pleasure, pain: they were identical, descending into the firmest most stubborn layer of life, a vegetative neutrality.

Joyce Carol Oates, The Goddess and Other Women 452, 460-61 (Vanguard 1974).

80 See, for example, Susan Brison, Aftermath: Violence and the Remaking of a Self 11 (Princeton 2002) (describing her own difficulties with intimacy following a rape). 


\section{Reckless disregard for consent.}

The traumas associated with rape would not necessarily make sex dangerous if the line between sex and rape were clear. If sex was sex and rape was rape, then sex would bring with it the emotional risk of rejection, but not annihilation. The line between sex and rape is far from clear though, both for the participants and for society at large. ${ }^{81}$ Men who acknowledge using force to get sex are often confused about whether they actually raped because not all women resist in the same way; some men simply assume consent if there is little resistance. ${ }^{82}$ Women are confused about their own role in expressing consent and often feel responsible for any failure to communicate nonconsent. ${ }^{83}$ One prominent researcher has concluded that when rape happens early in a relationship, misperception is likely the primary cause. ${ }^{84}$ The National Health and Social Life Survey found that 22 percent of women reported having been forced to do something sexual, ${ }^{85}$ while only 3 percent of men admitted to having used force. ${ }^{86}$ To quote the authors, "There seems to be not just a gender gap but a gender chasm in perceptions of when sex was forced." ${ }^{87}$

What this means is that one person's sex can be another person's rape. That is why casual sex is so emotionally dangerous; it might actually feel like rape to one of the participants. And, as with the physical

81 Consider the comments of both Richard Posner and Catharine MacKinnon. Compare Posner, Sex and Reason at 384 (cited in note 73) ("[R]ape appears to be primarily a substitute for consensual sexual intercourse."), with Catharine A. MacKinnon, Toward a Feminist Theory of the State 174 (Harvard 1989) ("Perhaps the wrong of rape has proved so difficult to define because the unquestionable starting point has been that rape is defined as distinct from intercourse, while for women it is difficult to distinguish the two under conditions of male dominance.").

82 See Eugene J. Kanin, Date Rape: Unofficial Criminals and Victims, 9 Victimology 95, $100-02$ (1984) (describing the results of a study concerning individuals charged with date rape and the various circumstances that lead to such incidents).

83 See Ronald Berger, et al, Sexual Assault in a College Community, 19 Sociological Focus 1,16 (1986) (providing examples of women describing their own feeling of responsibility for incidents of attempted sexual assault).

84 R. Lance Shotland, $A$ Theory of the Causes of Courtship Rape: Part 2, $48 \mathrm{~J}$ Soc Issues 127, 129 (Spring 1992) ("Many studies using a variety of different methods have shown that men perceive more sexual intent in others than do women.").

85 Robert Michael, et al, Sex in America: A Definitive Survey 223 (Little, Brown 1994).

86 Id at 228 . Of course it is possible that 3 percent of the men are raping 22 percent of the women, but this is highly unlikely. See id at 228-29:

These men would have to have multiple partners-about seven apiece-since so many women were forced, and they would have to revert to forcing sex with each of them. But that is unlikely because women who were forced usually were in love with the men or married to them, indicating that these were not short-term sexual liaisons. The women's descriptions of their partners were inconsistent with the notion that these men were having many partners... We think a more likely explanation is that most men who forced sex did not recognize how coercive the women thought their behavior was.

87 Id at 221. 
dangers associated with sex, these emotional dangers are visited disproportionately upon women. This is true both because women, on average, seem to view sex as more emotionally laden than do men, and because in those cases in which one person's sex is another person's rape, it is almost uniformly women who experience the act as rape. ${ }^{89}$

\section{Acquaintance rape and unprotected first encounters.}

The miscommunication, or lack of communication, that characterizes many acquaintance rapes can often be traced to recklessness. Recklessness can lead a man to complete the sexual act heedless of the consequences. From this perspective, it should not be surprising that acquaintance rapists rarely use condoms. Our interviews with both college rape counselors and with prosecutors underscore this basic correlation. Seasoned rape crisis counselors tend to report that condoms were "very rarely used" during acquaintance rape. Prosecutors report that few legal complaints of acquaintance rape concern protected sex.' A review of recent cases found that less than 1 percent (52 out of 5,898) of reported rape decisions in 2003 mention the use of a condom. Whether acquaintances or strangers, rapists tend not to use condoms.

88 Recent surveys suggest that adolescent girls value intimacy (that is, emotional connection) in sexual relationships more than adolescent boys do. See C. Rosengard, et al, Perceived STD Risk, Relationship, and Health Values in Adolescents' Delaying Sexual Intercourse with New Partners, 80 Sexually Transmitted Infections 130 (2004) (discussing the results of a survey to determine how long adolescents intend to wait prior to initiating sexual intercourse with a new partner and how successful the adolescents are in achieving the desired waiting period). For a discussion of how women seem to be more affected by the emotional consequences of sex, see Katharine K. Baker, Unwanted Supply, Unwanted Demand, 3 Green Bag 2d 103, 108-09 (1999).

89 All of the previously referenced studies of acquaintance rape, see notes $82-85$, involved men raping women.

90 Research assistants called dozens of rape crisis centers seeking information on the prevalence of condom use in acquaintance rape. A majority of the respondents were reluctant because of confidentiality concerns to share even the most general impressions about condom use. Others claimed that they had no impressions. But of six rape crisis centers that did respond, two reported that condoms were "very rarely used," one reported them "hardly ever used," one reported that condoms were used 16-25 percent of the time but emphasized that this was merely a general impression, one reported "not often," and one reported "more often than not." Only two of the respondents (one "very rarely used" and one "hardly ever used") were reported as being particularly confident in their assessment. See also Craig Wolff, Rapists and Condoms: Is Use a Cavalier Act or a Way to Avoid Disease and Arrest?, NY Times B1 (Aug 22, 1994) (reporting that the head of the San Francisco Rape Treatment Center estimated that " 15 to 20 percent of her cases involve condom rape").

91 We confidentially contacted a handful of prosecutors.

92 The 5,898 rape decisions were found in a Westlaw search of "rape!" in the All State and Federal Cases database. The 52 cases mentioning condom use were found by first searching the 
Rapists also tend to rape in first-time sexual encounters. In 2002, the National Crime Victimization Survey found that 84 percent of nonstranger, nonincest rapes were committed by "friends/ acquaintances" as opposed to "intimates." Rape by an intimate would, by definition, be a subsequent sexual encounter. Thus, the vast majority of nonstranger rapes are first-time sexual encounters. Similarly, a national study of college rape victims found that more than 60 percent of acquaintance rapes occurred in the context of "nonromantic" or "casual dating" (as opposed to "steady") relationships." Nine percent of women aged fifteen to twenty-four say their very first sexual experience was forced. ${ }^{\text {\% }}$ Rape does occur in subsequent sexual encounters. Researchers sometimes refer to this as "intimate partner rape" or "rape within sexually active couples," but the data suggest that a majority of nonincest, acquaintance rapes are unprotected firsttime sexual encounters.

Stepping back, we can now see that there are deep parallels between the physical and emotional harms of reckless sex, and that unprotected first-time sexual encounters play a crucial role in the incidence of both. To be sure, there are many unprotected first-time sexual encounters that do not result in the spread of infection or in nonconsensual sex. ${ }^{98}$ Still, unprotected first-time sexual encounters are

same data set for "rape! \& condom" and then reading the individual cases to verify whether the case referenced the defendant's use of a condom.

93 Prosecutors did mention contexts in which condoms were more likely to be used-for example, in cases where the rapist drugged the victim. See also Wolff, Rapists and Condoms, NY Times B1 (cited in note 90) (reporting that condoms are more likely to be used in violent rapes that the rapist spent time planning).

94 Callie Marie Rennison and Michael R. Rand, Bureau of Justice Statistics, National Crime Victimization Survey: Criminal Victimization, 2002 (DOJ 2003) (reporting victim-offender relationship statistics in rape and sexual assault cases).

95 See Mary P. Koss, et al, Stranger and Acquaintance Rape: Are There Differences in the Victim's Experiences?, 12 Psychology Women Q 1, 7 (1988) (excluding rape by a spouse or other family member from the category of acquaintance rape).

96 Alan Guttmacher Institute, In Their Own Right at 19 (cited in note 16). Another 25 percent of women in that age group say that though the sex was not forced, they did not want it to happen. Id. That means that over one-third of women did not want to be participating in their first-time sexual encounter.

97 Researchers distinguish between acquaintance rape that takes place between couples who have "not yet engaged in sexual intercourse" and those who have. Shotland, $48 \mathrm{~J}$ Soc Issues at 129 (cited in note 84). The distinction is important because intimate partner rape tends be more violent than first-time sexual encounter acquaintance rape. See Koss, et al, 12 Psychology Women $Q$ at 2 (cited in note 95) ("[T]he closer the victim-offender relationship, the more force that was used."). Moreover, the problems of rapists' misperception and miscommunication that loom large with regard to first-time sexual encounter acquaintance rape are less likely to be present with regard to intimate partner rape. Id. Our efforts here are directed to the former category.

98 There are also many instances of driving while intoxicated that do not result in an automobile accident. 
dominantly responsible for the right-hand tail in the distribution of sexual contacts, ${ }^{99}$ and it is this right-hand tail that gives such power to STD epidemics. Unprotected first-time sexual encounters are also the occasions for a substantial proportion of acquaintance rapes. ${ }^{100}$ Moreover, both of these harms are visited disproportionately on women.

\section{THE CURRENT LEGAL LANDSCAPE}

The last Part showed that two attributes of sex-sex that is a firsttime encounter between two particular people, and sex that is unprotected-when combined are strongly linked to both STDs and acquaintance rape. In light of these findings, we argue that the law should punish unprotected first-time sexual encounters. To some, this may sound like a radical or extreme idea. In this Part, we demonstrate that, while our proposal, as a whole, is novel, several of its constituent parts are not. In a variety of different ways, the law already addresses the difference between first-time and subsequent sexual encounters, the meaning of protected versus unprotected sex, and the physical endangerment that sex can create. The following Parts explore each of these areas of the law. Our proposal builds on the distinctions that the law already makes in order to better address the dangers that flow from unprotected first-time sexual encounters.

\section{A. First Encounters and Consent}

At first blush, it might seem that the law does not explicitly distinguish between first-time and subsequent sexual encounters in the

99 There are indications that public health organizations are beginning to stress the importance of unprotected first-time sexual encounters in determining the power of STD epidemics. For example, cross-country UN databases are beginning to collect such information, including "reported condom use with a non-regular sex partner." Office of Sustainable Development, 1 Health and Family Planning Indicators: A Tool for Results Frameworks 28, online at http://sara.aed.org/publications/cross_cutting/indicators/html/indicators1.htm (visited Feb 20, 2005).

100 But this does not mean that a majority of unprotected first-time sexual encounters are rape. Indeed, acquaintance rape probably represents only a small fraction of all unprotected first-time sexual encounters. For example, imagine that the probability of condom use during a consensual first-time sexual encounter is 65 percent; the probability of condom use during a nonconsensual first-time sexual encounter is only 1 percent. Bayes's theorem teaches that the probability of rape given non-condom use can still be quite small. If only 1 percent of first-time sexual encounters are nonconsensual, then the probability that an unprotected first-time sexual encounter will be nonconsensual rises to only 2.88 percent. $[\operatorname{Pr}(\mathrm{NC} / \mathrm{R}) \operatorname{Pr}(\mathrm{R}) / \operatorname{Pr}(\mathrm{NC})=$ $.35^{*} .01 / .356412$, where $\operatorname{Pr}(\mathrm{NC} / \mathrm{R})=$ probability of non-condom use given rape; $\operatorname{Pr}(\mathrm{R})=$ unconditional probability of rape; and $\operatorname{Pr}(\mathrm{NC})=$ unconditional probability of non-condom use (which equals $\operatorname{Pr}(\mathrm{NC} / \mathrm{R}) \operatorname{Pr}(\mathrm{R})+\operatorname{Pr}(\mathrm{NCNR}) \operatorname{Pr}(\mathrm{NR}))$.] While this conditional probability is 2.8 times higher than the assumed unconditional probability of acquaintance rape $(2.78$ percent/1 percent), it still suggests that, from a Bayesian perspective, non-condom use is not very probative of individual guilt. 
regulation of sexual assault. After all, rape is rape. But it has always been more difficult to prosecute rape in a case involving two people who have had a previous sexual relationship. The most prominent historical example of this was the de jure immunity of spouses to certain forms of rape prosecution. Many aspects of the marital immunity have been repealed, but remnants of it are still retained in several states. ${ }^{101}$

Indeed, the narrowing of the spousal immunity has been accompanied by a broadening of the scope of relationships entitled to distinctive treatment. The expansion of covered relationships began in 1962 when the Model Penal Code extended the marital rape immunity to include any "persons living as man and wife, regardless of the legal status of their relationship.", The expressly disparate treatment of a first-time and subsequent sexual encounter is also found in the Model Penal Code, which downgrades first-degree rape to second-degree if the victim "previously permitted [the assailant] sexual liberties." chelle Anderson explains that several states followed suit: "Delaware, Hawaii, Maine, North Dakota, and West Virginia enacted similar statutes that gave partial immunity to men who sexually assaulted women who had previously permitted them sexual contact. If a man had previous consensual sex with a woman, he could not be convicted of raping her.,"104

The disparate regulation of first-time and subsequent sexual encounters is also seen in the scope of rape shield laws. In recent years, forty-nine states and the District of Columbia enacted some form of rape shield law. ${ }^{105}$ While these laws generally exclude evidence of a victim's prior sexual history, nearly all jurisdictions, by statute or judicial decree, contain an exception: prior sexual behavior between the complainant and the defendant himself will not be excluded. ${ }^{106}$

The admission of evidence of prior sexual behavior, like the expanded immunity for subsequent sexual encounters, has everything to

101 See Michelle J. Anderson, Marital Immunity, Intimate Relationships, and Improper Inferences: $A$ New Law on Sexual Offenses by Intimates, 54 Hastings L J 1465, 1471-72 (2003) ("[T]wenty states grant marital immunity for sex with a wife who is incapacitated or unconscious and cannot consent. Fifteen states grant marital immunity for sexual offenses unless requirements such as prompt complaint, extra force, separation, or divorce are met.").

102 Model Penal Code $\$ 213.6(2)$ (ALI 1980).

103 Model Penal Code $\S 213.1(1)($ ii).

104 Anderson, 54 Hastings L J at 1521 (cited in note 101).

105 See Michelle J. Anderson, From Chastity Requirements to Sexuality License: Sexual Consent and a New Rape Shield Law, 70 Geo Wash L Rev 51, 81 n 150 (2002) (noting that Arizona is the only state without a rape shield law of any kind).

106 See Anderson, 54 Hastings L J at 1524 (cited in note 101) (stating that "evidence of the prior sexual behavior between a rape defendant and a complainant was relevant and admissible when he claimed the defense of consent"). 
do with presumptions about victim consent. As David Bryden and Sonja Lengnick see it:

Although previous consensual sex is obviously not conclusive evidence of consent on the occasion in question, nearly all commentators regard it as relevant, including thinkers as diverse as Susan Brownmiller, Herbert Wechsler, Susan Estrich, and Menachim Amir. At least superficially, this sort of evidence seems superior to evidence of intercourse with other men. ${ }^{107}$

Outside of formal legal rules, these disparate presumptions about consent may also impact police, prosecutor, and jury behavior. Anderson reports, "Police frequently have been unresponsive or hostile to women who report having been raped by their intimate partners. Some women have had to lie to police to get them to respond to rapes by intimates. ${ }^{, 108}$ Police are also more likely to find a complaint of subsequent encounter rape to be unfounded. ${ }^{109}$ Moreover, "rape scholars report that, if the defendant and his accuser had previously been lovers, juries are extremely reluctant to convict him.",

As a matter of raw statistics, the empiricism of the last Part suggests that a much larger proportion of first-time sexual encounters than subsequent sexual encounters are nonconsensual." Instead of reflecting this difference through the scope of first-degree rape, rape shields, or police investigation policies, our proposal creates a less pu-

107 David P. Bryden and Sonja Lengnick, Rape in the Criminal Justice System, 87 J Crim L \& Criminology 1194, 1369 (1997) ("There are ... two grounds on which one may decline a sexual overture: 'You're the wrong person' or 'this is the wrong time.' Evidence of sex with the defendant appears to eliminate the former possibility, something that evidence of sex with other men, or even of promiscuity, never does.").

108 Anderson, 54 Hastings L J at 1525-26 (cited in note 101).

109 Id at 1525 n 244 ("In a mail survey of 113 prosecutors in the 11 states in which no legal distinction existed between marital and non-marital rapes, responses to hypothetical rape cases containing corroborative evidence indicated that prosecutors were significantly less likely to believe that maximum charges would be filed in marital rape cases.").

110 Bryden and Lengnick, $87 \mathrm{~J}$ Crim L \& Criminology at 1201 (cited in note 107) (questioning whether jury unwillingness to convict if the defendant and accuser had previously been lovers is due to juror "prejudice[] against non-marital sex" or because "the defendant's version of events-seduction rather than rape-is more likely to be plausible").

111 Excluding incest, the statistics suggest that there are more first-time sexual encounter acquaintance rapes than subsequent sexual encounter acquaintance rapes while there are far fewer first-time sexual encounters than subsequent sexual encounters. See text accompanying notes 94-97. See also Callie Rennison, Bureau of Justice Statistics, National Crime Victimization Survey, Criminal Victimization 2001: Changes 2000-01 with Trends 1993-2001 8 (DOJ 2002), online at http://www.ojp.usdoj.gov/bjs/pub/pdf/cv01.pdf (visited Feb 20, 2005) (stating that 17 percent of rape victims report being assaulted by an intimate, while 46 percent report being raped by a friend or acquaintance). 
nitive but broader crime that focuses in part on the serious problem of nonconsensual first-time sexual encounters."

\section{B. Condoms and Consent}

Prior sexual activity with the defendant is just one of many factors the law considers when evaluating rape. Another, even more controversial, factor is the presence of a condom. Most of the controversy surrounding the relevance of condoms started with a single wellpublicized incident in Travis County, Texas. On September 17, 1992, Joel Rene Valdez, a twenty-seven-year-old house painter, entered the victim's home, held her at knifepoint, and began assaulting her. The victim then requested that Valdez use a condom, which he did. Later, the county prosecutor brought the evidence to a grand jury, which refused to indict. While the grand jury proceedings were secret, one grand juror later told the press that "some jurors believed that the woman's act of self-protection [by requesting a condom] might have implied her consent." "13 Valdez's defense lawyer was reported to say: "Consent is the only issue in a rape case, and my client feels that the use of a condom implied consent." ${ }^{, 14}$ The idea that a grand jury would refuse to indict because the victim of a stranger rape requested a condom sparked immediate public outrage. Prosecutors brought the case before a new grand jury one week later, and the new grand jury promptly indicted Valdez, who was eventually sentenced to forty years in prison."

112 We reject the idea of immunizing intimates from the possibility of first-degree rape prosecution. Rape is rape. Still, in the next Part we will embrace the idea of immunizing intimates from the separate crime of reckless sexual conduct. Indeed, by giving countenance to the heightened probability of nonconsensual sex with regard to a first-time sexual encounter, we might free the criminal law to narrow the immunities for subsequent encounter sex with regard to the more traditional crimes of sexual assault.

113 Ross E. Milloy, Furor Over a Decision Not to Indict in a Rape Case, NY Times A30 (Oct 25, 1992).

114 Id.

115 See Christy Hoppe, Rapist Gets 40 Years: Consent Defense in Condom Case Unsuccessful, Dallas Morning News 33A (May 15, 1993). See also Man Convicted of Rape; Victim Sought Condom, Chi Trib 9 (May 14, 1993) (reporting that the conviction drew "cheers in the courtroom"). Prior to his conviction, Valdez had argued on both the talk show Donahue and in a taperecorded statement played during the trial that the request for a condom meant consent. Roy Bragg, Woman Tells of AIDS Fear in Rape Case: Defendant Claims Condoms She Gave Him Implied Consent, Houston Chron A1 (May 12, 1993). However, as Travis County District Attorney David Counts observed, "[The condom defense] just doesn't fly. Jurors have common sense. This is not the $1930 \mathrm{~s}$, where people think premarital sex hardly exists. The condom defense represents a backwoods attitude." Cindy Loose and Patrice Gaines, Condom Doesn't Mean Consent, Jury Says: Panel Unsure Whether Woman Consented in Other Ways, Can't Reach Rape Verdict, Wash Post C3 (July 14, 1993) (noting that another jury in a similar case found that "the condom [request] was a 'non-issue' that quickly was dismissed"). 
In response to the Texas case, California and Florida passed statutes regulating evidence of condom use to prove the issue of consent. Although the wording of the statutes is slightly different, ${ }^{116}$ both have been interpreted narrowly, allowing condom use to come in as relevant to the issue of consent but not allowing condom use, by itself, to be sufficient to establish consent. ${ }^{117}$ Court decisions in other jurisdictions have also eschewed any per se rule inferring consent from either a victim's request for or a defendant's use of a condom, ${ }^{118}$ but courts do tend to admit evidence of a request to use a condom as evidence bearing on the issue of consent. ${ }^{.19}$

What is most important for this Article, however, is that courts in limited circumstances have taken the nonuse of a condom as evidence of nonconsent. For example, in State $v$ Ferguson, ${ }^{120}$ a Washington court upheld a second-degree assault conviction of a defendant who intentionally exposed a woman to HIV. The defendant argued that the woman's consent to sex was a defense to the charge. The court found that the woman in question "clearly consented to sex with a condom," but found that consent to protected sex with an HIV-infected man could not be construed as consent to the unprotected sex that actually occurred. $^{121}$

116 Compare Cal Penal Code $\$ 261.7$ (West 1999) ("[E]vidence that the victim suggested, requested, or otherwise communicated to the defendant that the defendant use a condom or other birth control device, without additional evidence of consent, is not sufficient to constitute consent."), with Fla Stat Ann $\$ 794.022(5)$ (West 2000) ("An offender's use of a prophylactic device, or a victim's request that an offender use a prophylactic device, is not, by itself, relevant to either the issue of whether or not the offense was committed or the issue of whether or not the victim consented.").

117 A California court held that "the jury ... could consider the alleged victim's request that a condom be used-or, in this case, the alleged victim's purchase of condoms-but that it could not determine that she had consented based solely on that evidence." People v Mokres, 2003 WL $22475856, * 5$ (Cal Ct App). Similarly, a Florida court held that "[u]nder the statute, condom use is a factor which can be argued and considered, but is not dispositive standing alone and must be considered in light of the other facts of the case." Strong $v$ State, 28 Fla L Weekly D378, 853 S2d 1095, 1098 (Fla Dist Ct App 2003).

118 See, for example, United States v Robinson, 2003 WL 21786065, *4 (Navy-Marine Corps Ct Crim App) (holding that "the victim's request that he use a condom could not honestly and reasonably be interpreted as consent when she continually said, "no"').

119 See, for example, In re J.J., 2000 WL 210440, *1 (Iowa Ct App) (noting that the victim's refusal to acknowledge the fact that she asked a friend for a condom undermined her credibility in testifying to the nonconsensual nature of the ensuing sexual encounter).

1201999 WL 1004992 (Wash Ct App), affd in part and revd on other grounds, 142 Wash 2d 631, 15 P3d 1271 (2001).

1211999 WL 1004992 at *6 n 32 (noting that "a person cannot give consent unless he or she has knowledge of all relevant facts; that there is no evidence that [the victim] knew Ferguson was not using a condom; and thus that [the victim] could not have consented to being assaulted with the virus"). 
Similarly, in Tyson $v$ State, ${ }^{122}$ an Indiana appellate court found evidence of a request for condom use to be evidence that the woman was not consenting to unprotected sex. In this case, the victim, D.W., had said to the defendant, "Please put a condom on," and "I don't need a baby." ${ }^{123}$ On appeal, the defendant argued that the jury should have been instructed that from this evidence the defendant might reasonably have believed the victim had consented. ${ }^{124}$ In rejecting this argument, the court reasoned:

[The victim's request], by itself, does not reasonably support the inference that D.W. consented to sexual intercourse. However, D.W.'s request, along with Tyson's response, that he would prefer to "ejaculate[] on her stomach and leg," and Tyson's afterintercourse statements - "I told you I wouldn't come in you. Don't you love me now?"- suggest only the inference that Tyson was aware that D.W. did not consent to unprotected sexual intercourse. ${ }^{125}$

The victim's request that her assailant use a condom did not constitute consent to sexual intercourse, but rather (in consideration with other evidence) expressed nonconsent to the unprotected sexual intercourse that actually occurred.

What should be clear is that the law already finds the use of condoms relevant, though not necessarily determinative. Our statute elevates the legal importance of condom use both because we agree with the courts that have already found that, in particularized settings, noncondom use can be indicative of nonconsent ${ }^{126}$ and because of the separate epidemiological harm of unprotected sex.

\section{Condoms and Reckless Physical Endangerment}

Finally, before proceeding with our proposed statute, it is important to recognize that there is currently some legal protection against reckless physical endangerment caused by sexual activity. Under the Model Penal Code, a person who, knowing he is infected with an STD, has unprotected intercourse without informing his partner of his con-

122619 NE2d 276 (Ind Ct App 1993).

123 Id at 295.

124 Id.

125 Id at 295 n 24 (internal citations omitted). The court held, as a matter of law, that these statements could not lead a reasonable person to believe that the defendant was reasonably mistaken as to the victim's consent. Id at 296.

126 See Brzonkala v Virginia Polytechnic and State University, 935 F Supp 779, 784 (WD Va 1996) (listing the allegation that "neither [defendant] used a condom" as a piece of evidence that supported the victim's rape claim), revd on other grounds, 132 F3d 949 (4th Cir 1997), vacd, 169 F3d 820, 889 (4th Cir 1999) (en banc). 
dition might well be guilty of reckless physical endangerment. ${ }^{127}$ Some states have enacted more particularized crimes of sexual endangerment. For example, the California Health and Safety Code provides:

Any person who exposes another to the human immunodeficiency virus (HIV) by engaging in unprotected sexual activity when the infected person knows at the time of the unprotected sex that he or she is infected with HIV, has not disclosed his or her HIV-positive status, and acts with the specific intent to infect the other person with HIV, is guilty of a felony punishable by imprisonment in the state prison for three, five, or eight years."

The phrase "unprotected sexual activity" is expressly defined in the statute to mean "sexual activity without the use of a condom.", For people who know themselves to be infected, California's statute imposes a requirement to either disclose this information to their partners or use a condom. Missouri also has an HIV prevention statute. It puts an unconditional duty of disclosure on infected persons who engage in sexual activity regardless of whether or not they use condoms. ${ }^{130}$

At first, Missouri's unconditional duty seems attractive. Condoms sometimes break, and uninfected people might reasonably want to know that they are assuming the risks associated with breakage in choosing to have sex with an infected person. But the Missouri statute may provide weaker incentives for condom usage. In Missouri, an infected person who uses a condom still runs a risk that his or her partner will claim that he or she was never told of the infection. Condom

127 Model Penal Code $\$ 211.1$ (creating criminal liability for "purposely, knowingly, or recklessly caus[ing] bodily injury to another").

128 Cal Health \& Safety Code $\$ 120291$ (a) (West Supp 2004). He might also be liable for the tort of negligent transmission of a contagious or infectious disease, see generally Theresa $\mathrm{K}$. Porter, Causes of Action for Negligent Transmission of Contagious or Infectious Disease, 22 Causes of Action 1 (2004), but such cases are rare and unlikely to be brought if either the defendant or the plaintiff has little money.

129 Cal Health \& Safety Code $\$ 120291(b)(2)$.

130 Mo Rev Stat § 191.677 (Supp 2004):

1. It shall be unlawful for any individual knowingly infected with HIV to . . . (2) Act in a reckless manner by exposing another person to HIV without the knowledge and consent of that person to be exposed to HIV, in one of the following manners: (a) Through contact with blood, semen or vaginal secretions in the course of oral, anal or vaginal sexual intercourse.

...

4. The use of condoms is not a defense to a violation of paragraph (a) of subdivision (2) of subsection 1 of this section.

See also Mo Rev Stat $\$ 567.020$ (2000) ("Prostitution is a class B misdemeanor unless the person knew prior to performing the act of prostitution that he or she was infected with HIV, in which case prostitution is a class B felony. The use of condoms is not a defense to this crime."). 
use won't give an infected person any legal advantage, so he may well not use one at all. This could lead to more infections. In the next Part, our proposal for a new crime of reckless sexual conduct will cleave closer to the California structure. Like California's statute, we will ask men to either use a condom or communicate more thoroughly with their partners. And as in California's statute, condom use will provide a safe harbor from liability.

Currently, notwithstanding the California and Missouri statutes, the legal regulation of physical sexual endangerment is incomplete and sporadic, and the legal regulation of emotional sexual endangerment is nonexistent. Cases alleging acts of physical endangerment based on unprotected sex have been brought and won against people infected with $\mathrm{HIV}^{131}$ but we have found only one (very old) case involving another STD, ${ }^{132}$ and one (very recent) case in which the defendant agreed to plead no contest to charges of reckless endangerment without any evidence of STD transmission. ${ }^{133}$ Furthermore, there simply is no crime of reckless emotional endangerment. The failure of the law to address emotional injuries associated with nonconsensual sex is a serious problem because, as mentioned, physical injury is often not the gravamen of the harm in rape. If the essential harm of rape can be an emotional harm, it would make sense to penalize its reckless infliction. Our proposed criminalization of reckless sexual conduct is tailored to do just that.

The last Part showed that two dimensions of sexuality (first-time sexual encounters and the lack of protection) are strongly related to

131 See, for example, People v Dembry, 91 P3d 431, 433 (Colo App 2003) (affirming a conviction for "reckless endangerment, as a lesser included offense of the charge of attempted manslaughter, based on [the defendant's] unprotected sexual contact with [the victim] while being HIV positive"); Smallwood v State, 343 Md 97, 680 A2d 512 (1996) (reversing the defendant's conviction for assault with intent to murder and attempted second-degree murder while upholding his conviction for reckless endangerment based upon three sexual assaults where the HIVpositive defendant did not use a condom while engaging in sexual intercourse).

132 State $v$ Lankford, 29 Del 594, 102 A 63 (1917) (holding that a husband can be guilty of assault and battery upon his wife for knowingly infecting her with syphilis). See also Alan Stephens, Transmission or Risk of Transmission of Human Immunodeficiency Virus (HIV) or Acquired Immunodeficiency Syndrome (AIDS) as Basis for Prosecution or Sentencing in Criminal or Military Discipline Case, 13 ALR 5th 628,678-79 (1993) ("[C]ourts have upheld vaccination and quarantine regulations aimed at other sexually transmitted infections or at diseases like smallpox, and [ ] many states have statutes making it a crime to expose others to sexually transmitted diseases.").

133 See Meggan Clark, Hypnotist Pleads Out on Sex Charges, New Haven Reg A1 (Jan 5, 2005). This plea (to three charges of reckless endangerment) was entered in return for the prosecution dropping one charge of witness tampering, two counts of voyeurism, one count of firstdegree sexual assault, and eleven counts of second-degree sexual assault. See id at A5. We would hope that adoption of our proposed statute would lead to a heightened awareness of the dangers of reckless sexual activity so that we would see many more prosecutions in many less egregious cases. 
two societal harms (STDs and nonconsent). These four permutations are depicted in the following matrix:

Type of Societal Harm

\begin{tabular}{|c|c|c|}
\hline & $S T D$ & Nonconsent \\
\hline $\begin{array}{l}\text { First-Time } \\
\text { Sexual } \\
\text { Encounter }\end{array}$ & & $\begin{array}{l}\text { Marital/Relationship } \\
\text { Exceptions }\end{array}$ \\
\hline Unprotected & $\begin{array}{c}\text { Reckless } \\
\text { Infliction; } \\
\text { Public Health } \\
\text { Codes }\end{array}$ & $\begin{array}{l}\text { Valdez and } \\
\text { Its Progeny }\end{array}$ \\
\hline
\end{tabular}

The big picture is that the law sporadically and in very limited ways has already taken notice of three of these four causal permutationsthe connection between first-time sexual encounters and consent, the connection between unprotected sexual encounters and consent, and the connection between unprotected sexual encounters and the spread of STDs. The missing fourth category, which we can now see is conspicuous by its absence, ${ }^{134}$ is legal rules reflecting the causal connection between first-time sexual encounters and the spread of STDs. ${ }^{1.5} \mathrm{In}$ the next Part we will try to fill this gap by proposing a law that is sensitive in a more systematic way to both first-time sexual encounters and unprotected sexual encounters.

\section{The AfFiRMative CASE For CRIMINALIZING RECKLESS SEX}

This Part lays out our affirmative case for a new crime of reckless sexual conduct. Put simply, our goal is to promote condoms and communication for first-time sexual encounters. The first Part showed that promoting condom use for this small subset of human sexuality could make progress on the problems of both sexually transmitted disease and acquaintance rape. Because condoms block the viruses and bacte-

134 In this respect, our project echoes that of Guido Calabresi and Doug Melamed, who also famously noticed a missing fourth category in a two-by-two box. See Guido Calabresi and A. Douglas Melamed, Property Rules, Liability Rules, and Inalienability: One View of the Cathedral, 85 Harv L Rev 1089, 1115-16 (1972).

135 One might see the targeted regulation of bathhouses as indirectly growing out of just this concern. See generally Randy Shilts, And the Band Played On (St. Martin's 1987) (discussing the controversy surrounding the decision of the San Francisco public health director to close public bathhouses in 1980 to help prevent the spread of AIDS and other STDs). See also Tom Farley, Cruise Control: Bathhouses Are Reigniting the AIDS Crisis. It's Time to Shut Them Down, Wash Monthly 36 (Nov 2002). 
ria that can be transmitted during intercourse, they prevent the spread of virtually all STDs. Because condom use requires more deliberation and patience than going without, expanded condom use is also likely to decrease those instances of intercourse in which one party fails to understand that the other party does not wish to engage in intercourse. Sex is often idealized as a kind of seamless, speechless act of mutually communicative physical expression. One rarely sees characters in film or on television requesting, explaining, or even talking as they glide effortlessly into and out of sex scenes. While these kinds of scenes may reflect reality for some couples, it is highly unlikely that they accurately depict first-time sexual encounters. The parties simply do not know each other well enough.

Miscommunication between the parties is likely to be greatest when the parties do not know each other. Our statute, though not as explicit in its communication forcing as those rules that require verbal consent before initiating a move to a higher level of sexual intimacy, ${ }^{136}$ would likely have comparable information-forcing effects. ${ }^{137}$ The application of a condom usually requires some interruption, a break from being carried away by the passion of the moment. It is that interruption - that pause - which is likely to give both parties the opportunity to ascertain and correct the kinds of misperception that can lead to rape. It gives all parties a required chance to reassess the situation and make sure the sexual intimacy should continue.

\section{A. A Model Statute}

To be precise about the contours of our proposal, we present here a model statute and in the margin briefly discuss a few drafting choices:

136 Antioch College adopted such a policy in 1993:

"Consent" is defined as the act of willingly and verbally agreeing to engage in specific sexual conduct. Previously agreed upon forms of non-verbal communication are appropriate methods for expressing consent. In order for "consent" to be valid, all parties must have unimpaired judgement and a shared understanding of the nature of the act to which they are consenting including safer sex practices. The person who initiates sexual conduct is responsible for verbally asking for the "consent" of the individual(s) involved. "Consent" must be obtained with each new level of sexual conduct. The person with whom sexual conduct is initiated must verbally express "consent" or lack of "consent." Silence conveys a lack of consent. If at any time consent is withdrawn, the conduct must stop immediately.

Antioch College, Sexual Offense Prevention Policy, online at http://www.antioch-college.edu/ community/survival_guide/Policies_Procedures/sopp.htm (visited Feb 20, 2005).

137 For more on the value of information-forcing default rules, see Ian Ayres and Robert Gertner, Filling Gaps in Incomplete Contracts: An Economic Theory of Default Rules, 99 Yale L J 87, 127-30 (1989). 


\section{Reckless Sexual Conduct}

(1) A person is guilty of reckless sexual conduct when the person intentionally engages in unprotected sexual activity with a person other than his or her spouse and these two people had not on an occasion previous to the occasion of the crime engaged in sexual activity.

(2) Affirmative Defense: Notwithstanding Section (1), it shall be an affirmative defense to any action brought under this article that the person with whom the defendant had unprotected sex expressly asked to engage in unprotected sexual activity or otherwise gave unequivocal indications of affirmatively consenting to engage in sexual activity that is specifically unprotected.

\section{(3) Definitions:}

(a) "Sexual activity" means penile penetration of a vagina or anus accomplished with a male or female. ${ }^{100}$

138 The number of nonconsensual first-time sexual encounters among people who are married is vanishingly small. The statute allows those few couples who do wait until their wedding night to forgo a condom when they do so. We include this marriage exception in large part because a significant number of states require schools to teach sexual abstinence before marriage as the only legitimate way to avoid pregnancy and STDs. See Alan Guttmacher Institute, State Policies in Brief: Sex and STD/HIV Education, online at http:/www.guttmacher.org/ statecenter/spibs/spib_SE.pdf (visited Feb 20, 2005). A student of one of these programs has never been taught how to use a condom and has been told that if he waits until marriage, he will be safe. Presumably it will not be at all difficult for people in this position to get consent to unprotected sex from their new spouse; we do not require them to do so. By the same token, state legislatures that oppose all forms of marriage exceptions could easily delete the words "other than his or her spouse."

139 A woman's past consent to an unprotected sexual encounter should not be admissible to show that she likely consented this time. We reach this result in accordance with the policy underlying rape shield laws. See FRE 412(a) ("The following evidence is not admissible in any civil or criminal proceeding involving alleged sexual misconduct . . . : (1) Evidence offered to prove that any alleged victim engaged in other sexual behavior."); United States $v$ Torres, 937 F2d 1469, 1472 (9th Cir 1991) (noting that the purpose of the rule is "to protect rape victims from the degrading and embarrassing disclosure of intimate details about their private lives"), quoting 124 Cong Rec H 11944 (Oct 10, 1978) (statement of Rep Mann). The inadmissibility of past consent is also in accordance with policies underlying the much older and time-tested statutory and common law prohibition against using prior acts to show action in conformity therewith. See, for example, FRE 404(b) ("Evidence of other crimes, wrongs, or acts is not admissible to prove the character of a person in order to show action in conformity therewith."); Spencer $v$ Texas, 385 US 554,560 (1967) ("Because such evidence is generally recognized to have potentiality for prejudice, it is usually excluded except when it is particularly probative."). But, as with current rape shield laws, there would likely be some exceptions. For example, if Kobe Bryant were prosecuted under our statute and if the prosecution intended to introduce evidence of vaginal injury to rebut a defense of consent, we would allow the defendant to introduce evidence of other recent sexual partners as a potential cause of that injury.

140 This is, purposefully, a very limited definition of sexual activity. It excludes oral sex, lesbian sex, and all forms of sexual activity that involve penetration with something other than a penis (a finger, a hand, a dildo). We exclude these activities even though some can be the cause 
(b) "Unprotected sexual activity" means sexual activity without the use of a condom.

(c) "Occasion of the crime" includes the twelve-hour period after the two people engage in sexual activity for the first time.

(4) Sanctions:

(a) Sentence: The crime of reckless sexual conduct is punishable by imprisonment in the state prison for up to three months, or a fine. ${ }^{1.3}$

of STD infection and others can be the result of coercion. STDs can be transmitted through oral sex or from a cut on a finger inserted into an anus or vagina. People rape with their hands as well as with their penises. In order to try to maximize legitimacy and therefore enforcement, however, we opt for a less comprehensive definition. For instance, requiring condom use for oral sex, even first-time oral sex, could well be perceived as such an infringement on the essence of the activity that the regulation itself would be perceived as illegitimately intrusive and disruptive. This would decrease the likelihood of effective enforcement. For reasons explained in Part III.D.2, our hope is that extensive enforcement will shift norms sufficiently to eventually allow for a more comprehensive regulation. Reckless coercion is also less of a concern with oral sex because it is much harder to remain ignorant of a partner's lack of consent to oral activity. This is not to say that oral sex cannot be coerced. Clearly, it can be, but the behavior of the defendant in such situations is usually purposeful, not reckless. Including objects other than a penis in a definition of penetration, while much less likely to be considered intrusive, would incorporate many acts that carry virtually no risk of STD transmission, and again, would include acts that are much less likely to be coerced recklessly.

141 This definition is intended to include both the male and the female condom. This definition would immunize defendants from prosecution even if they used a nonlatex condom. Alternative versions of the statute might insert the word "latex" or "male" before "condom."

142 The purpose of this section is to create a twelve-hour window of scrutiny surrounding the first sexual encounter of a particular pair. Under this section, a defendant could not avoid liability by arguing that he and the other person used a condom in their first-time sexual encounter and then later within the twelve-hour period engaged in an unprotected sexual encounter. To fall outside the scope of section (1), all sexual activity within the first twelve hours of the first sexual activity (that is, the first penetration) would need to be protected. While we have not included a statute of limitations in our model statute, we recommend that a state apply either a statute of limitations commensurate with its statute of limitations for the crime of rape or sexual assault, see Rape, Abuse, and Incest National Network, Statute of Limitations for Prosecuting Rape and/or Sexual Assault, online at http://www.rainn.org/statutesoflimitationcrim.pdf (visited Feb 20, 2005) (listing state statutes of limitations for rape and sexual assault ranging from no limitation to four years for simple rape), or a relatively short statute of limitations with a reporting requirement. For example, the statute could read: "Prosecution for reckless sexual conduct may be commenced within two years of the commission of the offense if the victim reported the offense to law enforcement authorities within three months after the commission of the offense." See, for example, 720 ILCS 5/3-5 (West 2004) (conditioning the statute of limitations on a victim report within two years after the commission of the offense).

143 Jurisdictions too uncomfortable with criminal sanctions in this area could adopt a civil regime in which a state attorney general brought charges, with any fines collected going to the state. Civil measures might be enforced more broadly because prosecutors, judges, and jurors, wary of stigmatizing a defendant too strongly, might be more willing to impose civil sanctions. Our preference is for criminal sanctions for two reasons. First, we think the stigma associated with a nonfelonious criminal sanction strikes the right balance between deterrence and incre- 
(b) Sexual Offender Status: The court shall not register a person as a sexual offender because the person was found guilty of reckless sexual conduct.

\section{B. Statutory Analysis}

It seems that our statute imposes a kind of strict liability on those who engage in unprotected sex to which a partner did not obviously agree. But prosecutors must prove that the defendant knowingly engaged in an unprotected first-time sexual encounter. ${ }^{144}$ We title the crime "reckless sexual conduct" not because the prosecutor must show a reckless state of mind, but because knowingly engaging in this behavior is statutorily defined to be reckless. This kind of legislative definition of recklessness is not unique. As Lloyd Weinreb notes, "A great many [ ] specific negligent or reckless acts are proscribed by legislation." ${ }^{145}$ For instance, California's criminal code presumes that one is negligent in the operation of a machine, engine, or other device if a fire originated from the operation of that device. ${ }^{146}$ The prosecution does not have to prove state of mind. Virtually all states criminalize driving while intoxicated because it is considered per se reckless, regardless of whether the prosecution can prove reckless behavior. George Fletcher writes that "the culpability of negligence is [in] failing to bring to bear one's faculties to perceive the risks that one is taking." and the failure of many people to understand both the physical and emotional dangers of sexual conduct, it is highly appropriate that legislators adopt a proposal that underscores the comprehensive dangers of unprotected sex.

In what follows, we will show how, from three alternative analytic perspectives, the criminalization of reckless sex is likely to increase condom use. From an individualistic, rational actor perspective, the law promotes condom use by raising the cost of unprotected sex. From

mentalism. It is strong without being too punitive. Second, a great many defendants are likely to be young and judgment proof. Prison or alternative sentencing (community service work in an AIDS ward, for instance) may be the only effective sanction. Lawmakers might also consider enhancing the penalty for recidivists or people who are found to have had unprotected first-time sexual encounters with a number of different partners.

144 "Purposefully," "knowingly," "recklessly," and "negligently" are the four levels of culpability adopted in the Model Penal Code. See Model Penal Code $\S 2.02$.

145 Lloyd L. Weinreb, Criminal Law: Cases, Comment, Questions 270 (Foundation 7th ed 2003).

146 See Cal Pub Res Code $\$ 4435$ (West 2001).

147 George P. Fletcher, The Theory of Criminal Negligence: A Comparative Analysis, 119 U Pa L Rev 401, 415 (1971). See also H.L.A. Hart, Negligence, Mens Rea and Criminal Responsibility, in A.G. Guest, ed, Oxford Essays in Jurisprudence 29, 45 (Oxford 1961) (arguing that there are instances when carelessness should be treated like intentional wrongdoing). 
a behaviorist perspective, the law appropriately offsets and harnesses cognitive biases. And from a social norms perspective, the law expresses a gentle nudge toward the use of condoms. In the remainder of this Part, we show from rational actor, behavioral, and social norm perspectives that the predictable consequences of criminalizing reckless sexual conduct will be to decrease the rate of both STDs and acquaintance rape.

\section{Rational Actor Analysis of the Statute}

This statute, only two hundred words long, would increase the use of condoms. Because condom use is a safe harbor that makes firsttime sexual encounters fall outside the scope of the statute, couples (and, as we will argue below, particularly men) will have an incentive to use condoms to avoid the risks involved in having to establish the affirmative defense (that the other person solicited or unequivocally indicated consent to unprotected sex).

1. Decreases in both unprotected and nonconsensual sex.

This general shift toward protected sexual encounters can be decomposed into different components. Figure 2 divides the landscape of sexuality into a stylized two-by-two box. One dimension distinguishes between sex that is protected and unprotected; the other dimension distinguishes between situations where a potential defendant does and does not have sufficient indications of consent. Acquaintance rape would live in the "insufficient" consent row.

FIGURE 2

\begin{tabular}{|c|c|c|}
\hline & Protected & Unprotected \\
\hline $\begin{array}{c}\text { Sufficient } \\
\text { Consent }\end{array}$ & & \\
\hline $\begin{array}{c}\text { Insufficient } \\
\text { Consent }\end{array}$ & & \\
\hline
\end{tabular}


Some couples who would engage in unprotected consensual sex will shift to protected consensual sex. Because the lack of protection will be consensual, they would not need to avoid the statute, but in order to eliminate any strategic or spiteful use of the statute by a partner later, they will use protection. This shift is depicted by arrow A. This movement is clear progress in the fight against STDs.

For other couples, the break in the action caused by the attempt to put on a condom will present an opportunity for the parties (primarily women) to better express whether or not they truly consent. The result of this improved communication will be to more explicitly inform men that sex (either protected or unprotected) is not wanted. Studies suggest that at least some acquaintance rapists will not proceed if they truly learn the woman is not consenting. ${ }^{148}$ This reduction in the amount of unprotected, nonconsensual sex is depicted by arrow $B$ and would be clear progress in the fight against acquaintance rape. It would also reduce the rate of STD transmission.

At other times, the opportunity for clearer communication will lead to better evidence of genuine consent. This condom-induced opportunity for communication is an opportunity for a conversation about sex that may make both parties feel more in control of their decisions. Thus some of the unprotected, ambiguously consensual sexual encounters in the shadow of the new crime will become protected, consensual sexual encounters. This transformation is depicted by arrow $\mathrm{C}$ and represents progress in the fights against both STDs and acquaintance rape. ${ }^{149}$

Finally, some men who had been engaging in unprotected, nonconsensual sex will opportunistically substitute toward protected, nonconsensual sex in order to fall inside the protection of the statute. This shift is depicted by arrow D. Movements along the insufficient consent row do not reduce the amount of acquaintance rape. Nevertheless, the movement toward condom use still has a beneficial effect with regard to the spread of STDs. Protected acquaintance rape, though still rape, produces lower risks of infection (and pregnancy) than unprotected acquaintance rape. Protected acquaintance rape will not extinguish the emotional harm of acquaintance rape, but it will reduce the physical harm. This is one of the reasons that some rape victims ask that their assailant use a condom.

148 See Part I.B.1.

149 This better evidence of genuine consent depicted by arrow $\mathrm{C}$ may also trigger a move into a different quadrant of the figure. In some cases in which two persons are having ambiguous unprotected sex, the conversation forced by this law will define the consensual nature of the sex, but they may decide that rather than having consensual protected sex, they are going to have consensual unprotected sex. 
Thus, hyperrational actors are likely to substitute toward condom use and/or conversation in the shadow of a law that requires that a man either use a condom or stand ready to prove, by a preponderance of the evidence, that his partner gave unequivocal indications of consent. On several margins, we would expect to see a reduction in unprotected first-time sexual encounters (represented by arrows A, C, and D). And on one margin, we would expect to see not just a shift in the type of sexuality but an absolute reduction in the level of sexuality (arrow B). Because of increased communication (and because nonconsensual sex is harder to accomplish with a condom) we expect that, in the shadow of the new law, some men who previously would have engaged in acts of unprotected, nonconsensual sex will stop having sex. ${ }^{150}$

2. Decreases in justice system error.

In addition to these four margins of benefit, the criminalization of reckless sexual conduct is likely to decrease the overall "errors" in the criminal justice system. At present we are stuck in an equilibrium where it is widely acknowledged that a large percentage of all acquaintance rapists go unpunished. After investigating the causes and effects of violence against women and reviewing data from several jurisdictions, the Senate Judiciary Committee concluded that 98 percent of rape victims "never see their attacker caught, tried and imprisoned." failures to report rapes to the authorities, failures to arrest, and failures to convict. For example, crime victim survey data from the mid1990 s suggest that each year an estimated 500,000 women are victims of some form of rape or sexual assault. "In 1994, only 102,096 rapes were reported to authorities, and ultimately there were only an estimated 36,610 arrests for forcible rape." ${ }^{153}$ An arrest does not assure conviction. One scholar found that "[t]he likelihood of a [rape] complaint actually ending in conviction is generally estimated at 2 to 5 percent." ${ }^{\text {,ist }}$

150 It is also possible that some men and women who would have engaged in unprotected, consensual sex acts will be so put off by the idea of using condoms that instead of switching to protected consensual sex (arrow A), they will choose not to have sex. This result would have been depicted by an arrow paralleling arrow B but starting in the upper right quadrant.

151 Senate Committee on the Judiciary, The Response to Rape: Detours on the Road to Equal Justice, S Rep No 103-52, 103d Cong, 1st Sess 1 (1993).

152 Ronet Bachman and Linda E. Saltzman, Violence Against Women: Estimates from the Redesigned Survey, Bureau of Justice Statistics Special Report 1 (1995).

153 Federal Bureau of Investigation, Uniform Crime Reports for the United States 199424 (DOJ 1995).

154 Joan McGregor, Introduction, Symposium, Philosophical Issues in Rape Law, 11 L \& Phil 1, 2 (1992). 
The criminalization of reckless sexual conduct is likely to help ameliorate this problem. For many instances of acquaintance rape, the new law creates the first practicable means of obtaining a conviction-albeit for a crime with a modest sanction. A central goal of rape law reforms "has been to facilitate prosecution of acquaintance rape cases,"15s but several studies suggest that the reforms have been largely unsuccessful at increasing the rate of acquaintance rape conviction. At the end of the day, it is often extremely difficult for prosecutors to prove beyond a reasonable doubt that the victim did not consent."

In contrast, it will be fairly easy to prove beyond a reasonable doubt that the sex was unprotected and that it was a first-time sexual encounter. The presence of the defendant's ejaculate found in a timely examination can, along with other circumstantial evidence (concerning the exigencies of the intercourse), provide powerful evidence that the sex was unprotected. Often the short duration of any acquaintance between the defendant and the victim strongly indicates that the sex was a first-time sexual encounter. To some it is controversial whether William Kennedy Smith, Mike Tyson, or Kobe Bryant engaged in nonconsensual sex, but it is fairly clear that each engaged in an unprotected first-time sexual encounter. ${ }^{158}$ Therefore, the criminalization of reckless sexual conduct is likely to reduce the problem of acquaintance rapists going completely unpunished.

The criminalization of reckless sex might also help deter statutory rape. Prosecutors are often very reluctant to prosecute as rape a crime in which the victim willingly consented. ${ }^{1.9}$ Our statute could help in two ways. First, its widespread enforcement should help elevate people's awareness that teenage girls engaging in unprotected first-time

155 Bryden and Lengnick, $87 \mathrm{~J}$ Crim L \& Criminology at 1283 (cited in note 107). See also Patricia Searles and Ronald J. Berger, The Current Status of Rape Reform Legislation: An Examination of State Statutes, 10 Women's Rts L Rep 25-26 (1987); Dripps, 92 Colum L Rev at $1780-81$ (cited in note 73 ).

156 See, for example, Bryden and Lengnick, $87 \mathrm{~J}$ Crim L \& Criminology at 1253 (cited in note 107).

157 See Katharine K. Baker, Sex, Rape, and Shame, 79 BU L Rev 663, 690 (1999):

Unlike stranger rapes, date rape trials are nothing but credibility contests. There is no fruit of the crime to be produced, no weapon to be traced and no mistaken identity. Everyone concedes that both parties were there ... and that intercourse did take place.... Given how easily the sexual acts could be consensual in these cases, it is very hard for the prosecution to remove all reasonable doubt that they were not.

158 See Susan Estrich, Palm Beach Stories, 11 L \& Phil 5 (1982); Kobe Bryant Police Interview at 28 (cited in note 1 ).

159 See Michelle Oberman, Turning Girls into Women: Re-Evaluating Modern Statutory Rape Law, 85 J Crim L \& Criminology 15, 23 (1994) (quoting a Los Angeles District Attorney's office as saying, "[I]t is the policy of this office not to file criminal charges where there is consensual sex"). 
sexual encounters are put at risk for grave, lifelong injuries. The more people realize how dangerous sex can be, the more they may be willing to prosecute those who recklessly subject minors to those dangers. Second, as with acquaintance rape, even if a prosecutor is not willing to prosecute someone for statutory rape, he or she may be willing to prosecute or accept a plea for the lesser crime of reckless sexual conduct. Again, those who now escape punishment altogether will at least be subject to some criminal sanction.

There are, however, two types of justice errors: (1) failing to punish the guilty and (2) punishing the innocent (sometimes referred to as Type I and Type II errors, respectively). By subjecting acquaintance rapists and statutory rapists to at least some punishment, the crime of reckless sexual conduct is likely to reduce Type I errors, but, by shifting the burden on the issue of consent from the prosecutor to the defendant and making it easier for prosecutors to convict, it might increase Type II errors. Some defendants who were in fact engaging in an unprotected sexual encounter in which the other person had given "unequivocal indications of affirmatively consenting" to unprotected sexual activity may be unable to establish this fact by a preponderance of the evidence. These men would be wrongfully convicted.

The size of this Type II error will crucially turn on the extent to which the defendants' sexual partners are willing to bring false claims of nonconsensual, unprotected first-time sexual encounters. Current research suggests that the propensity of women to make false reports of acquaintance rape is extremely low. ${ }^{160}$ As Bryden and Lengnick summarize, "The conventional wisdom now is that the proportion of false reports is negligible, perhaps as low as $2 \%$, a figure said to be comparable to that for most other major crimes." new law will make it easier for prosecutors to convict, the problem of Type II errors is likely to be limited by general reluctance of "victims"

160 See, for example, Julie A. Allison and Lawrence S. Wrightman, Rape: The Misunderstood Crime 205-06 (Sage 1993) (discussing briefly the rate of false accusation related to rape and stating that it is comparable to that of other major crimes); Morrison Torrey, When Will We Be Believed? Rape Myths and the Idea of a Fair Trial in Rape Prosecutions, 24 UC Davis L Rev 1013, 1028 (1991) (asserting that rape complaints are as likely to be true as reports of any other crime); Harry J. O'Reilly, Crisis Intervention with Victims of Forcible Rape: A Police Perspective, in June Hopkins, ed, Perspectives on Rape and Sexual Assault 89, 96-97 (Harper \& Row 1984) (analyzing false reports in a six-month period in New York City and concluding that there were only five cases in which women maliciously told lies); Carolyn J. Hursch, The Trouble with Rape 81-87 (Nelson-Hall 1977) (refuting an earlier study on high rates of false reports and finding that women rarely give false reports); Susan Brownmiller, Against Our Will: A Victim of Society and the Law 386-87 (Simon \& Schuster 1976) (describing the problem of false accusations as a myth "which has found expression in male folklore since the Biblical days of Joseph the Israelite and Potiphar's wife").

161 Bryden and Lengnick, 87 J Crim L \& Criminology at 1298 (cited in note 107). 
to bring false claims. ${ }^{162}$ Moreover, given that the current equilibrium is so skewed toward Type I errors, the net number of judicial errors will almost certainly decrease-even if we abide by the social tradeoff that it is better to let twenty guilty go free rather than to convict even one who is innocent.

The risk of Type II errors is also one that potential defendants can easily avoid. As long as courts are accurate in determining what constitutes a protected first-time sexual encounter, potential defendants can avoid prosecution merely by choosing to use a condom. From an ex ante perspective, they hold the keys to their own jailhouse. In contrast, potential victims of acquaintance rape under current law have no easy means of reducing the risk of Type I error. Switching from a regime with very large and unavoidable Type I errors to one with small but avoidable Type II errors is a tradeoff that society should embrace.

\section{Could criminalization induce more acquaintance rape?}

Figure 2 emphasized predictable shifts in the manner of preexisting levels of sexuality-which in the shadow of the new law became more protected and more consensual. It is also important to consider whether the law would change not just the types of sex but the levels of sex. We already suggested one such effect when we argued that the law would deter some unprotected, nonconsensual sexual encounters. This was represented by arrow B. We should pause to consider whether the law would cause some rapes to occur that otherwise would not have taken place.

For example, might it be possible that potential perpetrators might, because of the new crime, feel immunized to rape as long as they use a condom? If so, this might not just cause a shift from unprotected to protected rape (as depicted by arrow D) but also create an absolute increase in the total amount of nonconsensual sex - which is depicted by the additional arrow $\mathrm{E}$ in Figure 3 -as instances of no sex become instances of protected, nonconsensual sex.

162 It may be that Type II errors would increase because more women would be willing to bring false claims if they had a higher chance of success; but remember, the complaining victim receives no objective benefit from a successful prosecution. The only way she could clearly benefit from a regime in which there was a greater chance of conviction would be if she took the opportunity to try to blackmail a potential defendant. This is, of course, illegal, and it seems unlikely particularly because in order to ensure a higher chance of prosecution, the victim would have to act promptly after the sexual encounter to prevent the DNA evidence from going stale. See note 168 . 
FIGURE 3

\begin{tabular}{|c|c|c|}
\hline & Protected & Unprotected \\
\hline $\begin{array}{c}\text { Sufficient } \\
\text { Consent }\end{array}$ & & \\
\hline $\begin{array}{c}\text { Insufficient } \\
\text { Consent }\end{array}$ & & \\
\hline
\end{tabular}

Initially, we should be skeptical of this argument. While the use of a condom immunizes a first-time encounter rapist from prosecution under the reckless sexual conduct statute, it does not immunize the rapist from prosecution under any of the preexisting sexual assault laws. Our proposal is to enact an additional, complementary crime, not a substitute form of liability. Accordingly, we should not expect to see any reduction in current levels of deterrence for acquaintance or stranger rape.

However, a more subtle form of the argument is that jurors deciding cases involving preexisting claims of sexual assault will stop convicting if there is a condom and thus raise the bar for proving traditional rape. The idea here is that jurors will come to think (notwithstanding the formal law) that non-condom use is a prerequisite for finding nonconsent, and thus as a practical matter will read into the rape statutes a de facto requirement that the sexual encounter was unprotected. Potential rapists who had been deterred under the earlier law will respond to this change by beginning to rape (or raping more) with condoms.

The possibility that our law might actually increase the amount of nonconsensual sexual encounters is an important challenge to our proposal, but for several reasons, we think it is highly unlikely that this additional crime will reduce deterrence. First, the initial grand jury in the Valdez case in Texas notwithstanding, jurors evaluating stranger rape cases are not likely to be significantly affected by evidence of 
condom use. Valdez went to jail for forty years. ${ }^{163}$. It is increasingly implausible that jurors would acquit an alleged acquaintance rapist just because he wore a condom. ${ }^{164}$ Moreover, if legislators are worried about this, they can simply draft the kind of statutes that California and Florida did, making clear that condom use is not proof of consent. Second, we are skeptical that jurors would frame the elements of reckless sex as illuminating the elements of rape. As emphasized below, these crimes have radically different sanctions (with regard to prison time, stigma, and potential labeling of a convict as a "sex offender"). Failing to wear a condom in a first-time sexual encounter is more likely to come to be seen as reckless (just as driving while intoxicated is reckless) rather than as strong evidence that the victim failed to consent.

Third, we should be skeptical of the claim of reduced deterrence because as a statistical matter it would be hard to imagine a regime with a lower probability of punishments. Estimates are that less than 2 percent of acquaintance rapists are criminally punished. This probability cannot fall below zero. It is implausible that reductions in the probability of conviction would induce an influx of additional nonconsensual sexual encounters. Put more conservatively, it is unlikely that any increases in rape caused by reduced probability of punishment (arrow E) would not be more than offset by the benefits of increased communication and protection, and the benefits of reduced judicial error, described above.

4. Defending the de facto unequal treatment of reckless women.

Perhaps the strongest objection to our statute pertains to its gender effects. While facially neutral with regard to sex, as a practical matter women will be largely beyond prosecution. Men may not be able to prove by a preponderance of the evidence that a woman consented to unprotected sex, but a woman defendant will normally be able to prove that the man "gave unequivocal indications of affirmatively consenting to engage in sexual activity that is specifically unprotected." The man's choice to place his unsheathed penis inside the woman in most cases would provide an unequivocal indication. Thus, if we put aside the truly aberrational case of a woman who puts a gun

163 Rapist Who Agreed to Use Condom Gets 40 Years, NY Times A6 (May 15, 1993).

164 See Loose and Gaines, Condom Doesn't Mean Consent, Wash Post at C3 (cited in note 115). But see Kevin Cullen, Woman Alleges Rape Wasn't Prosecuted; Contends Police Left Case Because She Asked Men to Wear Condoms, Boston Globe Metro 1 (Nov 17, 1994). 
to the man's head and coerces unprotected sex, we should expect that women would rarely, if ever, be prosecuted under such a statute. ${ }^{165}$

This de facto immunity initially seems unfair, because women can be reckless too in instigating, precipitating, or just willingly consenting to an unprotected first-time sexual encounter. Why is it fair that the man who consents to unprotected sex must run the risk of prosecution, when the woman who consents to unprotected sex does not? Put differently, why should a male who engages in unprotected sex bear the burden of establishing an affirmative defense, when the very act of unprotected sex establishes the defense for the reckless female?

One way to amend our model statute to remove this asymmetry would be to eliminate the affirmative defense, thereby transforming the crime into a strict liability offense-making both men and women criminally liable for intentionally engaging in an unprotected firsttime sexual encounter. Women would lose their de facto absolute immunity, and men would lose the limited immunity offered by the affirmative defense. To explain our preference for our proposed statute instead of the strict liability alternative, we must explain both why we prefer a limited consent defense for men, and why we prefer a much broader de facto immunity for women.

Our preference for a limited consent defense for men grows out of particular notions of culpability. Even if having an unprotected first-time sexual encounter is socially reckless, it is reasonable to consider a male defendant to be less culpable if his partner actively solicited his participation. ${ }^{166}$ Active solicitation or unequivocal indications of consent are extenuating or mitigating factors that, as we will discuss below, track the contours of traditional affirmative defenses. Just as entrapment can be an affirmative defense for defendants who are egged on by government officials, ${ }^{167}$ the broad contours of our affirmative defense (with a purposeful degree of drafting lenity due to difficulties of proof) afford immunity to male defendants who were likely

165 While this Part speaks of de facto immunity for women, a more general characterization would be to say that the statute would produce de facto immunity for a person who was penetrated. Thus, with regard to an unprotected first-time sexual encounter between two men, the man who was penetrated would be de facto immune from prosecution, while the man who penetrated would not. We will return to specific concerns raised by applying the statute to same-sex couples. See notes $245-50$ and accompanying text.

166 From the perspective of acquaintance rape, it is obviously relevant to a defendant's culpability whether or not the woman consented. But, as argued in Part IV.A, the affirmative defense is constitutional only if it does not represent an essential element of the crime. Accordingly, we explicitly want to ground the defense as a way of mitigating the culpability of acting recklessly with regard to the social risk of STDs.

167 See Model Penal Code $\$ 2.13(2)$. 
to have been encouraged (or seduced) to behave recklessly with regard to the spread of STDs.

With regard to the de facto immunity for women, one must keep in mind that the law is not likely asymmetric in practice. When a woman is reckless too, her male partner is more likely to be able to establish the affirmative defense. He will have a true story to tell and she will have to lie in order to refute it. So when the woman is reckless, both the man and the woman are likely to be immune from prosecution. The real asymmetry would arise with regard to a woman who was in fact an active and willing participant in the unprotected sex but who then falsely accused the man of forcing nonconsensual sex. This theoretical concern is again undermined by the social science research indicating that few women make false claims in this arena. ${ }^{168}$

Moreover, our preference for a limited consent defense for men grows out of our twin concerns for both acquaintance rape and STDs. The de facto gender asymmetry of the statute mirrors the de facto gender asymmetry of acquaintance rape and the de facto genderbased injury asymmetry of STDs. The vast majority of acquaintance rapists are male. ${ }^{169}$ From the perspective of making progress on acquaintance rape it is almost completely unproblematic to have a larger de facto immunity for women. The class of people hurt by the emotional dangers of sex is overwhelmingly female. As discussed, women are also much more likely to be infected with, and if infected, seriously injured by, STD transmission. This law protects those who are most likely to get hurt. As the Supreme Court stated in upholding gender specific statutory rape laws, "Because virtually all of the significant harmful . . . consequences of teenage pregnancy fall on the young female, a legislature acts well within its authority when it elects to punish only the participant who, by nature, suffers few of the consequences." ${ }^{170}$

Most important, making women de facto immune preserves their freedom to come forward and report instances of reckless sex when they did not give unequivocal indications of consent. A strict liability alternative to our statute would massively chill women's incentives for reporting both reckless sex and rape. A woman would be much less

168 See notes $160-61$ and accompanying text. It is possible that more women will report falsely in this instance because the chances of conviction are greater. But conviction is easier only if the prosecution has ejaculate to prove unprotected sex. A woman might make a false claim right away, in time to secure a rape kit sample. But if the desire to make a false claim is triggered by traditional reasons like anger, rejection, or jealousy, it is less likely that those motives will surface until the DNA evidence has expired.

169 See, for example, Rennison and Rand, Criminal Victimization at 10 table 4 (cited in note 94). In $2002,149,620$ victims of nonstranger rape were women while 16,500 were men.

170 Michael M. v Sonoma County Superior Court, 450 US 464, 473 (1981). 
likely to report a partner's reckless behavior if by doing so she was subjecting herself to prosecution for the same act. More important, a strict liability regime would aggravate the current underreporting of acquaintance rape. A woman who was in fact raped by an acquaintance in a first-time sexual encounter without a condom would have to worry that in reporting the rape she would expose herself to potential prosecution for the crime of reckless sexual conduct. Strict liability versions of the reckless sex statute-even those that nominally immunized rape victims from prosecution - are intolerable because they are likely to exacerbate the underreporting of acquaintance rape. ${ }^{17}$ The last Part rejected the possibility that the model statute might perversely lead to more acquaintance rape, but making both men and women strictly liable for engaging in an unprotected first-time sexual encounter might do just this.

Granting defendants an affirmative defense in these settings perversely increases the likelihood of their conviction. There are likely to be more convictions of men under our model statute than would occur under an identical statute that removed the affirmative defense. In a world without the defense, women are less likely to report nonconsensual reckless sex. So even though the affirmative defense gives men more of a chance of defending against an accusation, on net it exposes acquaintance rapists to a higher risk of prosecution. Our statute might represent the rare instance in which granting defendants an affirmative defense makes it easier for prosecutors to convict.

171 Indeed, while we began this discussion by asking whether we should narrow the asymmetry in immunity for men and women, the importance of preserving reporting incentives for victims of acquaintance rape caused us to consider whether we should instead broaden the asymmetry by giving women a per se defense against prosecution. We ultimately rejected this possibility. First, the explicit sexual discrimination of such a statute would trigger heightened scrutiny under the Equal Protection Clause, though this would not necessarily kill the statute. A de jure immunity for the penetrated person in an unprotected first-time sexual encounter would likely be constitutional both because it does not expressly discriminate on the basis of sex and because it furthers the important government interest of increasing the frequency of victim reporting, as discussed above. (It also gives the immunity to the person much more likely to be infected.) Our deeper concerns are prudential. We worry that the social meaning of this de jure disparate treatment against men might undermine the effectiveness of the statute. Because women can indeed be instigators of reckless sex, it is unfair to expressly immunize them from any possibility of prosecution. The appearance of unfairness is important. And, as discussed above, one can imagine pathological circumstances (gun-to-the-head scenarios) in which a woman would in fact be prosecutable.

172 One should worry whether the statute would also chill men's willingness to test themselves for STDs. A man might worry that evidence that he had become infected with an STD would be evidence that he had engaged in unprotected sex and might occasion further inquiry from prosecutors about whether it was a first-time sexual encounter. We think this is a small concern. The clinic's information about the test results should be covered by a traditional privilege. It should be possible to preclude a link between testing and prosecution. 
To summarize, without the consent defense, our statute would do more harm than good because no one would report violations given that he or she would be inculpating himself or herself. Just as unacceptably, no woman would report a rape that she was not absolutely sure she could prove. The rape reporting rate would sink much lower than its already tragically low level. The burden placed on men to prove consent, though in practice greater than the burden placed on women, is both logical and minimal. It is logical because unprotected first-time sexual encounters are very dangerous. The statute presumes that people do not consent to such dangerous activity. The burden placed on men is also remarkably small-affecting, on average, seven occasions in their life. If men are that worried about women asserting false claims, all they need do is put on a condom.

Failure to use a condom already subjects men to a much harsher strict liability regime than the one we are proposing. If the sexual encounter results in pregnancy, regardless of what the man represented about his intentions ${ }^{173}$ and regardless of what the woman represented about her use of birth control, ${ }^{174}$ the man is liable for child support for eighteen years of the child's life. Our statute lets him prove consent in order to avoid liability; paternity laws give no such opportunity.

\section{A Cognitive and Norms Analysis of the Statute}

The rational actor analysis of the preceding Part will be unpersuasive (and may even be offensive) to certain readers who view evaluations of marginal carrots and sticks as poor predictors of human behavior. We are particularly agnostic about the extent to which rationality and rational response to incentives are a wellspring of human sexual behavior. The arrows of the prior Part suggest the theoretical directions of movements in sexuality, but not the size of the effects.

Ultimately, however, we believe that an even stronger case for the criminalization of reckless sexual conduct can be made by taking into account both the cognitive biases that affect individuals and the ways that social norms affect groups. The normative "consilience" of these three approaches - that rational actor, cognitive bias, and norms

173 See, for example, Moorman $v$ Walker, 54 Wash App 461, 773 P2d 887, 889 (1989) (concluding that although the father of a child had stated to the mother that he did not want to have children, he could not avoid his parental responsibilities); Budnick $v$ Silverman, 805 S2d 1112 (Fla App 2002) (voiding a pre-conception agreement between the parties that the biological father would not be named in paternity because the right to child support is the child's right).

174 See, for example, Wallis v Smith, 130 NM 214,22 P3d 682 (NM App 2001) (holding that a father could not sue in tort to recover compensatory damages stemming from his girlfriend's misrepresentations about birth control); L. Pamela P. v Frank S., 59 NY2d 1, 449 NE2d 713 (1983) (holding that a woman's misrepresentations with regard to birth control are irrelevant to the question of the man's child support obligation). 
analysis all are shown to support the model statute-enhances our confidence in the proposal. ${ }^{1 / 5}$

This Part will first suggest that taking into account the ways that individual decisionmaking tends to diverge from rationality strengthens the case for criminalization. We then suggest how a new crime of reckless sexual conduct could play an important role in a broader campaign to strengthen the current norm of using a condom in firsttime sexual encounters.

\section{Cognitive departures from rational decisionmaking.}

The increase in condom use in the shadow of the initial publicity about AIDS ${ }^{176}$ is good news for rational actor theorists. It suggests that the rationality assumption can still aid in predicting behavior. The fact that condom usage rose is a strong indication that behavior does respond to incentives. The idea that people just will not stop "in the heat of the moment" is belied by the increased condom usage in response to AIDS fears.

But the gains that were made in condom use during the AIDS scare now show signs of ebbing. ${ }^{1 \pi}$ As the threat of AIDS becomes more remote (or as the disease appears to be more treatable) in developed countries, people seem to be less likely to use a condom. ${ }^{178}$ It may be that the scare did not last long enough for people, particularly heterosexuals, to internalize the risk of contracting HIV.

More importantly, there is scant evidence that people have ever internalized the comprehensive risks of unprotected sex. ${ }^{179}$ Behavioral psychologists have identified a variety of cognitive biases ${ }^{180}$ that can

175 See Edward O. Wilson, Consilience: The Unity of Knowledge (Knopf 1998) (arguing that truth lies in the unity of knowledge rather than the compartmentalization of knowledge). See, for example, Ian Ayres and John Braithwaite, Responsive Regulation: Transcending the Deregulation Debate (Oxford 1992) (arguing that the use of both persuasion and sanctions can lead to a proper level of government regulation).

176 See Aral and Holmes, Social and Behavioral Determinants of the Epidemiology of STDs at $58-64$ (cited in note 41 ).

177 See Cornelis A. Rietmeijer, et al, Increases in Gonorrhea and Sexual Risk Behaviors Among Men Who Have Sex with Men: A 12-Year Trend in Analysis at the Denver Metro Health Clinic, 30 Sexually Transmitted Diseases 562, 562 (2003) (finding that the incidence of STDs in men who have sex with men has increased in recent years and arguing that this is a result of a "change toward higher risk-taking behaviors").

178 See id at 566 (finding that 17 percent of men who have sex with men stated they were less concerned about HIV because of the availability of better treatment).

179 See id (finding a high degree of inconsistent condom usage for both men sleeping with men and men sleeping with women over the course of the study).

180 See Daniel Kahneman and Amos Tversky, Prospect Theory: An Analysis of Decision Under Risk, 47 Econometrica 263 (1979) (developing the model of prospect theory as an alternative to the traditional expected utility model); Christine Jolls, Cass R. Sunstein, and Richard Thaler, A Behavioral Approach to Law and Economics, 50 Stan L Rev 1471 (1998) (arguing for 
cause men to systematically underestimate the risks of unprotected sex. The low salience of STDs and acquaintance rape-especially with respect to first-time sexual encounters-may bias the risk downward. ${ }^{181}$ Availability bias ${ }^{182}$ and optimism or self-serving bias ${ }^{183}$ can lead people to underappreciate the risks of both acquaintance rape and STDs. The tendency of many men to treat acquaintance rape as something other than "real rape" may cause them to underappreciate both its danger to the victim and the likelihood that they would engage in it. ${ }^{184} \mathrm{Be}$ cause successful prosecutions are so rare, many men may not have cognitively available examples that could provide cues for their own action.

Prosecutions under the proposed law would increase the cognitive salience of acquaintance rape, thus increasing the likelihood that men would fear it. Indeed, in an interesting way our law "economizes on misogyny" to promote condom use. The kind of man who does not particularly care about the quality of a woman's consent may be the same kind of man who will find the risk of this new crime to be most salient. This is because men who hold women in low esteem are likely to overestimate the risk of being falsely accused. This "irrational" fear of false rape accusations is well established in the literature. ${ }^{185}$ The

the application of bounded rationality to the discipline of law and economics); Jeffrey J. Rachlinski, The Uncertain Psychological Case for Paternalism, 97 Nw U L Rev 1165 (2003) (endorsing the view that individuals do not rely on rule-based systems; rather, human choice is heuristically driven).

181 It might at first seem that acquaintance rape is already - without our proposed statute quite salient. Certainly, in the last twenty years, people have become much more aware that date rape is relatively common and illegal. But there is still a great deal of confusion about what date rape is. As the studies cited earlier suggest, see Part I.B.1, many men may rape without realizing that a woman is not consenting. Jurors and other observers often fail to condemn actions that the law defines as rape. See Katharine K. Baker, Once a Rapist?: Motivational Evidence and Relevancy in Rape Law, 110 Harv L Rev 563, 588-89 (1997). The idea of date rape is cognitively available to people, but a concrete understanding of what constitutes date rape is not nearly as available.

With regard to STDs, while the AIDS epidemic of the 1980s and 1990s clearly made the risk of AIDS more salient, the risk of other STDs remains remarkably remote. How many people are aware that 25 percent of teenagers may carry an STD? See text accompanying note 19. How many people know that one in six men aged fifteen to forty-nine have genital herpes? See text accompanying note 16 . How many people appreciate the physical risks that women run if they expose themselves to STDs other than HIV? See text accompanying notes 33-39.

182 Availability bias refers to people's tendency to appreciate and internalize only those risks that are obvious - or readily cognitively available.

183 Self-serving bias refers to people's tendency to discount the likelihood that they could be hurt.

184 See Susan Estrich, Real Rape 8-9 (Harvard 1987) (using a liberal prosecutor's failure to file charges against a women's boyfriend because she had no bruises and she did not fight to show that men do not count acquaintance rape as "real rape").

185 See, for example, Bryden and Lengnick, $87 \mathrm{~J}$ Crim L \& Criminology at 1207 n 81 (cited in note 107). 
statute harnesses this misogynist bias to offset the various other factors that make the risks of STDs and nonconsensual sex of low salience.

Lack of public awareness likely also leads to an underappreciation of the risks of infecting another with an STD. The STD victims of reckless sex are seldom publicized. Magic Johnson's series of unprotected dalliances might have caused the death of dozens of other people, but these causal connections are rarely, if ever, discussed. Even when we hear about people who died from AIDS, the death is not connected to the sexual source, nor is risky sexual behavior linked to the infection. The more people who are prosecuted under the statute, the more cognitively available those causal connections will become.

Optimism and self-serving biases are also likely to contribute to individuals' tendency to downplay their likelihood of being infected. Importantly, the risk of infection stands in a very different place cognitively than assessment of the risk of pregnancy (which might also be underassessed because of optimism and self-serving biases). ${ }^{185}$ One does not need to think badly about one's choice of partner to worry that an unprotected sexual encounter may lead to pregnancy. The same is not true about assessing the risk of STD infection. To worry about being infected by one's partner is to focus on that person's sexual history and to worry about how and why he or she has been infected. Particularly at the moment of deciding to engage in intercourse, some people may want to reduce the salience of their partner's prior sexual relationships. This disassociation bias could lead to an irrationally low level of condom use.

Appreciating that men and women may underestimate the true risks of unprotected first-time sexual encounters strengthens the rationales for government intervention. Thus, our crime can be justified now not only by the traditional "externalities" argument - men and women don't take into account the harms to other people when they engage in reckless sex-but also as a form of cognitive "paternalism" aimed at increasing the perceived risk of engaging in unprotected first-time sexual encounters. ${ }^{187}$ If the risk of acquaintance rape and

186 Surveys consistently show that women (and to a lesser degree men) find the risk of pregnancy to be more salient in their decision to use condoms than the risk of contracting an STD. However, as women have gained more control over contraception (and abortion), the salience of the pregnancy risk has decreased. See Rosengard, et al, 80 Sexually Transmitted Infections at 133-34 (cited in note 88) (noting that young women delay sex due to the importance of health and intimacy in relationships, as well as the perceived risk of STDs, but making no explicit reference to pregnancy). This may well have led to an increase in unprotected sex.

187 For further discussion on cognitive paternalism in public policy, see Cass R. Sunstein and Richard H. Thaler, Libertarian Paternalism Is Not an Oxymoron, 70 U Chi L Rev 1159 (2003) (arguing that one can use the preexisting default rules and framing effects that inevitably exist in 
STD infection is currently of low salience, then a new statute-which expressly defines and criminalizes reckless sex-can increase the perceived risk of engaging in unprotected first-time sexual encounters. This is an example of "debiasing through law."

\section{Reinforcing existing norms.}

Both the rational actor and cognitive analyses focused on the individual actor as the unit of analysis. It is also useful to consider, at a more aggregate level, what impact a crime of reckless sex might have on the social meaning of an unprotected first-time sexual encounter. This Part argues that criminalization can play a useful role in a larger strategy of reinforcing an emerging social norm to use condoms in first-time sexual encounters.

a) The message. To begin a discussion on changing social norms, it is important to emphasize that most people already use condoms in first-time encounters. According to a recent national study, more than 60 percent of men report using condoms in casual relationships. ${ }^{189}$ For older readers who may be apt to extrapolate from their

an individual's decisionmaking process to lead to policy gains without decreasing freedom of choice).

188 See Christine Jolls and Cass R. Sunstein, Debiasing Through Law (John M. Olin Law \& Economics Working Paper No 225 (2d Series), Sept 2004), online at http://www.law.uchicago.edu/ Lawecon/WkngPprs_201-25/225-crs-debiasing.pdf (visited Feb 20, 2005). Or more precisely, Christine Jolls has suggested to us that our proposal might be seen as a mixture of the insulation and debiasing strategies. Our proposal insulates bias insofar as it increases the severity of consequences (penalties) associated with particular behavior and thus tries to create incentives not to engage in such behavior. This aspect parallels the way that tort law imposes greater liability to reduce consumer product consumption levels in response to optimism bias by consumers. But the law also can be seen to debias the choices of men in particular. The very existence of the model statute might increase the availability of some of the negative occurrences from first-time sexual encounters; in that respect it might have the effect of reducing the gap between perceived and actual probabilities. By creating a new category of illegality, we increase the availability of the underlying harm and thus debias people.

189 See Koray Tanfer, et al, Condom Use Among U.S. Men, 1991, 25 Fam Planning Perspectives 61, 64 table 3 (1993) (reporting that 61 percent of men questioned who reported a one night stand in the last four weeks had also reported using a condom in that period). See also Patricia O'Campo, et al, Contraceptive and Sexual Practices Among Single Women with an Unplanned Pregnancy: Partner Influences, 25 Fam Planning Perspectives 215, 218 table 5 (1993) (finding that women with two or more sexual partners in the last twelve months are 3.2 times more likely to report condom use); Elizabeth L. Paul, Brian McManus, and Allison Hayes, "Hookups": Characteristics and Correlates of College Students' Spontaneous and Anonymous Sexual Experiences, 37 J Sex Rsrch 76, 81 (2000) (reporting that 81 percent of individuals who had experienced at least one hookup including sexual intercourse also reported using a condom); Laura Kann, et al, Youth Risk Behavior Surveillance-United States, 1997, 47 Morbidity \& Mortality Wkly Rep 1, 19 (1998) ("Nationwide, among currently sexually active students, $56.8 \%$ reported that either they or their partner had used a condom during last sexual intercourse."). 
own historical experiences, this may come as a surprise. ${ }^{190}$ But in this age of AIDS (and herpes and chlamydia), things have changed. The great majority of people report that they aspire to condom use in casual sexual encounters."

Promoting condom use in first-time sexual encounters is thus not an attempt to instill a radically new social norm. It is instead an attempt to reinforce a preexisting norm and aspiration of most people in society. Accordingly, the criminalization of reckless sex is not a "just say no" strategy. "Just say no" campaigns run the risk of ambiguous signals. The listeners may think that they are being asked to play by the rules when no one else is. Playing by the rules in such a situation is very unlikely to be seen as "cool." reckless is not "Just say no to unprotected sex"; rather it is "Just be like everybody else!" "193

190 The new prevalence of casual sex is a major theme of Tom Wolfe's book, Hooking $U p$ (Farrar 2000): "In the year 2000, in the era of hooking up, 'first base' meant deep kissing ('tonsil hockey'), groping, and fondling; 'second base' meant oral sex; 'third base' meant going all the way; and 'home plate' meant learning each other's names." Id at 7. See also Posner, Sex and Reason at 1 (cited in note 73) (arguing that judges' extrapolation from their own sexual history often leads them astray).

191 In a study of a family practice center's patients, 92 percent reported that they thought it was acceptable to insist on condom use, and 88 percent reported that it was acceptable for women to refuse sex if the man does not want to use a condom. David L. Stewart, et al, Attitudes Toward Condom Use and AIDS Among Patients from an Urban Family Practice Center, $83 \mathrm{~J}$ Natl Med Assn 772, 774 table 2 (1991). See also Françoise Caron, et al, Psychosocial Predictors of Intention and of Condom Use Among Adolescents Attending High School, presented at the 12th Annual Canadian Conference on HIV/AIDS Research (2003), reprinted in 14 Can J Infectious Diseases supp A, 81 (finding that 50.9 percent of adolescents strongly intended to use a condom, while 49.1 percent were less assertive in their intention). But not everyone aspires to condom use. See Paul Gertler, Manisha Shah, and Stefano M. Bertozzi, Risky Business: The Market for Unprotected Commercial Sex 2 (unpublished presentation, given at the Northeast Universities Development Consortium Conference at Yale University, Oct 17-19, 2003), online at http://www.econ.yale.edu/seminars/NEUDC03/shah_paper.pdf (visited Feb 20, 2005) ("We estimate that sex workers received a 23 percent premium for unprotected sex from clients who requested not to use a condom, and this premium jumped to 46 percent if the sex worker was considered very attractive."); Susan M. Kegeles, Nancy E. Adler, and Charles E. Erwin, Jr., Adolescents and Condoms: Associations of Beliefs with Intentions to Use, 143 Am J Diseases Children 911 (1989) (finding that despite an understanding of condom effectiveness in preventing diseases, adolescents did not take this fact into consideration when deciding whether to use condoms).

192 See Dan M. Kahan, Social Influence, Social Meaning and Deterrence, 83 Va L Rev 349 (1997) (putting forward a "social influence theory of deterrence," which places importance on how individual decisionmaking is influenced by how others perceive such actions).

193 This is an application of "social-norms marketing." See Mark Frauenfelder, SocialNorms Marketing, NY Times F100 (Dec 9, 2001). Back in 1990, Professor Perkins at Hobart and William Smith College discovered that most students thought that they were drinking less than the average - and, thus, increased their consumption to be more like others. When the true drinking data was publicized, and students discovered that few of their peers had more than five drinks at a party, peer pressure to drink more than five was greatly reduced. The results were so successful in reducing heavy drinking that this approach has been employed throughout the 
The statute might also promote a new social norm by changing the social meaning attached to using a condom. As Cass Sunstein notes: "[S]ocial norms can also be an artifact of social meaning. Suppose that the social meaning of condom use is a confession [or] an accusation. ... If so, there will be a social norm discouraging condom use." ${ }^{194}$ In a separate article, Sunstein describes a New York Times article in which

some teenage boys said that they don't use condoms even though they really would like to ... and the reason is that use of a condom is an accusation or a confession, and neither is very romantic. That is, the social meaning of condom use is to say, you probably have AIDS, or I might have AIDS, and neither of those assumptions is very desirable to make in the relevant situation. ${ }^{19}$

Criminalizing unprotected first-time encounter sex can give men an independent rationale for using a condom. In the shadow of our statute, reaching for a condom would not imply that the man was infected or that he worried about the woman's being infected, it might merely be an attempt to comply with both the law and the more general social norm to wear a condom while engaging in all first-time sexual encounters.

Because the average person has fewer than ten sexual partners in a lifetime, the new law regulates a small handful of events in the lives of most Americans. Because most Americans already use condoms in first-time sexual encounters, it is a law that asks most of us to change our behavior in fewer than five events in our lives. Admittedly, those five events may be significant ones. The first kiss is more meaningful than the hundredth kiss. Nonetheless, the required change in behavior is minimal, usually aspired to anyway, and easy to avoid with communication if desired. ${ }^{196}$ The only people significantly affected by this law are those people whose current behavior is the most risky-the small minority of citizens who are frequently engaging in unprotected firsttime sexual encounters.

California State University system and beyond. As the New York Times reports: "Rather than telling students to 'Just say no!' They are saying, in effect, 'Just be like everybody else.'" Id.

194 Cass R. Sunstein, Social Norms and Social Roles, 96 Colum L Rev 903, 928 (1996).

195 Cass R. Sunstein, Should Government Change Social Norms?, Speech for the AEI Bradley Lecture Series (Nov 12, 1996), online at http:/www.aei.org/news/newsID.18910/news_detail.asp (visited Feb 20, 2005). See also Jennifer Steinhauer, At a Clinic, Young Men Talk of Sex, NY Times C7 (Sept 6,1995) ("Many times, some of the young men said, introducing condoms into their sexual relationships raises suspicions in their partners."). Condom use can also be a source of embarrassment for men. See note 228.

196 For couples who have any discussion about birth control, all the statute does is require that they add one more topic to the conversation. 
Our statute is accordingly an example of what behavioral economists have recently termed "asymmetric" interventions. ${ }^{197}$ The idea here is that, when possible, government should prefer interventions that tend to constrain the behavior of the most cognitively biased individuals, while leaving relatively unaffected those people whose choices are relatively unbiased. ${ }^{188}$ The statute is structured to do just this. It asks the most of the right-hand tail of population - people who have dozens or hundreds of sexual partners-but asks little if anything of the majority of people who already use condoms for first-time sexual encounters.

All-encompassing campaigns for "safe sex" or "100 percent condom use" are, if taken literally, unreasonable. If all couples used condoms all the time, the human race would cease to exist. ${ }^{199}$ There is no valid policy reason for making monogamous long-term sexual partners use condoms. Programs advocating 100 percent condom use for sex workers, on the other hand, are quite laudable ${ }^{200}$ but insufficient. Condom advocates have yet to offer precise advice as to where to draw the line between these two poles. We draw the line at first-time sexual encounters. ${ }^{201}$ While this standard for condom usage is underinclusive of optimal "safe sex" practices, criminal statutes are often structured to target the most egregious antisocial behavior.

197 See generally Colin Camerer, et al, Regulation for Conservatives: Behavioral Economics and the Case for "Asymmetric Paternalism," 151 U Pa L Rev 1211 (2003). This article focuses on asymmetric interventions to correct biased choices of individuals that hurt themselves, but the same idea can be applied to interventions to correct biased choices of individuals that disproportionately hurt others as well. We might term this latter intervention as an example of "asymmetric internalization" of externalities. Our statute's asymmetric quality is supported by both rationales - as the most reckless individuals may both underestimate the risk to themselves and the risks to others created by their actions.

198 The government's ban on cotton infant pajamas is a clear counterexample of asymmetric intervention. The nonsmoking majority had to forgo the pleasures of cotton because a few smokers would tend to incinerate their children.

199 Of course, condoms sometimes break or are otherwise ineffective in stopping pregnancy. But if condoms were used 100 percent of the time, the human population would likely not be able to sustain itself and thus within some number of generations, under this pathological hypothetical, become an endangered species.

200 See, for example, Nicole Rajani, Fighting for Their Health, India's Sex Workers Mobilize, amfAR Global Link, online at http://www.amfar.org/cgi-bin/iowa/td/feature/ record.html? record=91 (visited Feb 20, 2005); WHO Promotes 100\% Condom Use Among Sex Workers in Asia, AIDS Wkly (Sept 8, 2003), online at http://www.walnet.org/csis/news/ world_2003/aidsweekly-030908.html (visited Feb 20, 2005).

201 Many people now distinguish between casual and noncasual sex as the dividing line for mandatory condom use. A problem with this framing is that it is more susceptible to a kind of self-delusion bias ("I really thought he/she was the one") in ways that undermine the effectiveness of the norm. In contrast, there is no internal ambiguity in how to apply the norm that condoms should always be used the first time you have sex with someone else. 
Another possibility would be to require that condoms be used 100 percent of the time when partners are not married, but not necessarily at all if the partners are married. If universally accepted this rule would likely end STD epidemics. ${ }^{202}$ A bright-line marriage rule could be an effective public health measure, but it would seriously infringe on the sexual expression rights of unmarried people. Same-sex couples in many states would never have the option of non-condom use, and neither would faithful unmarried straight couples. Faithful couples who begin a relationship without infection should, regardless of their marital status, retain the ability to engage in unprotected sex-even for nonprocreative purposes -if they so desire..$^{203}$ Our model statute aims at reinforcing a much less demanding (and therefore more sustainable) norm. Unlike the impracticable demands of 100 percent condom use no matter what, or 100 percent condom use for all nonmarital sex, the statute requires 100 percent condom use for all firsttime sexual encounters. ${ }^{204}$

b) The punishment. We have intentionally drafted the model statute to have a mild sanction. We have done this because if the criminal sanction is too strong, there is not likely to be widespread enforcement. ${ }^{205}$ Widespread enforcement will be critical to the statute's efficacy. As Dan Kahan has argued, attempts to change a norm by severely punishing that which has previously been unaddressed or underenforced are often unsuccessful. ${ }^{206}$ One reason for this is that decisionmakers enforcing the laws (police officers, prosecutors, judges) often balk at imposing strict penalties for offenses that many people do not view as extremely offensive. ${ }^{207}$ Unprotected sex would almost certainly fall into this category. Prosecutors and jurors will not work to seriously condemn someone whose only proven offense is not

202 This prediction assumes neither that spouses are faithful nor that they begin marriage unprotected. As long as all spouses used condoms during extramarital intercourse there would be very little communication of STDs into or outside of the marriage unit, and the communication of STDs within married couples that would be countenanced by this rule would not be sufficient to sustain an ongoing STD epidemic.

203 We should not forget that non-condom use for marital sex is a religious requirement for observant Catholics and Orthodox Jews. See Elaine Jarvik, Birth Control Is a Complex Issue, Deseret News E01 (Mar 8, 2003).

204 But even here, the statute accommodates the desire for an unprotected first-time sexual encounter of those who communicate sufficiently.

205 See Dan M. Kahan, Gentle Nudges vs. Hard Shoves: Solving the Sticky Norms Problem, $67 \mathrm{U}$ Chi L Rev 607, 610 (2000) ("As severity of condemnation . . . increases, the percentage of decisionmakers who are willing to enforce law declines.").

206 See id at 623-40. Among Kahan's examples are date rape, domestic violence, and drug, alcohol, and smoking prohibitions.

207 Id at 610-11. 
wearing a condom in a first-time sexual encounter. In all probability, those decisionmakers do not view the behavior as all that bad.

Those same decisionmakers might be willing to punish the behavior a little though, particularly as they learn more about the dangers associated with it. The more the behavior gets punished somewhat, the easier it will become to punish in general and the more people will be punished. The more people are punished, the more certain punishment will be, the more people will become aware of the dangers, and the less likely people will be to engage in the behavior. ${ }^{208}$ The less people engage in the behavior, the easier it will be to ratchet up the punishment in order to proportionally reflect the degree of harm involved. ${ }^{209}$

Increased punishment should also help change the norm of indifference with regard to whether one's partner is consenting to sex. Changing this norm should lead to much more effective prosecution of acquaintance rape. The crime of reckless sexual conduct creates a category of sexual offense that is not rape or sexual assault, but is still criminal. Reckless sexual conduct should not be presented as a substitute for rape. It is not to be prosecuted, punished, or perceived as such. It is instead a crime that tries to control behavior that can lead to rape, just as drunk driving laws try to control behavior that can lead to manslaughter. If most people do not conflate a DUI conviction with a manslaughter conviction, people need not conflate a conviction for reckless sex with a rape conviction.

The recent history of rape enforcement shows all too clearly how resistant juries and prosecutors are to punishing offenders who have not raped in the traditional sense. ${ }^{210}$ There are embedded images of who a rapist is ${ }^{211}$ and who a rapist is not. ${ }^{212}$ When the alleged rapist and the facts of the crime alleged fail to conform to the embedded cultural definition of rape, the crimes do not get prosecuted, or if prosecuted,

208 This is another way of describing how to reverse availability bias.

209 This entire cycle is described by Kahan, 67 U Chi L Rev 607 (cited in note 205).

210 See generally Schulhofer, Unwanted Sex at 17-46 (cited in note 72).

211 In characterizing the arguments for amendments to the Federal Rules of Evidence that allow the defendant's prior acts of rape to be admitted in rape trials, one proponent described rapists as a "small class of depraved criminals," David J. Karp, Evidence of Propensity and Probability in Sex Offense Cases and Other Cases, 70 Chi Kent L Rev 15, 25 (1994), notwithstanding the evidence establishing that rape appears to be much more a function of social norms than individual psychology. Many men across many classes commit rape. See Baker, 110 Harv L Rev at 576-78 (cited in note 181) (presenting evidence that the tendency to rape is prevalent in many men and is not considered an abnormality).

212 Consider the comments of one man who observed a gang rape trial of seven college students in Michigan: "I don't believe she was raped ... I believe they ran a train on her." Chris S. O'Sullivan, Acquaintance Gang Rape on Campus, in Andrea Parrot and Laurie Bechhofer, eds, Acquaintance Rape: The Hidden Crime 140 (Wiley 1991) (noting that people often do not view decent college students as rapists and arguing that "group sexual assault is considered normal behavior for some groups of young men in our society"). 
do not result in convictions. ${ }^{213}$ The simple fact is that the public at large often refuses to see the "nontraditional" rapist as a rapist at all and therefore refuses to either mark him or punish him as such. After an acquittal in a well-publicized college gang rape, one juror explained that the main concern of some jurors was not wanting "to ruin the boys' lives." ${ }^{214}$ Decisionmakers may be willing to ruin the life of a "real rapist," but they will not impose comparable punishment for what they see as a less severe crime. The crime of reckless sexual conduct will make it easier to punish callous sexual behavior precisely because the punishment will not ruin the defendants' lives.

Many reformers have worked very hard to get jurors, judges, police, and prosecutors to see that acquaintances can be sexually assaulted in ways that are equally as devastating as stranger rape, if not more so. ${ }^{215}$ This work is important and their claims are valid, but the attempt to illuminate the realness of some acquaintance rape has obscured the moral wrong of other behavior that may not constitute or could never be proved to be rape. In emphasizing that acquaintance rapists are "real rapists," the movement has had the effect of erasing the moral category of reckless sexual conduct. Under their approach, a man is either a "rapist" or legally not culpable. Our statute imposes a less severe punishment precisely because what we are attacking directly is recklessness, not the result of recklessness. We also intentionally choose to exempt convicted defendants from registering on a state's list of sexual offenders. Jurors deciding these cases should not be determining whether the defendant is a rapist or the kind of serious sexual offender whose whereabouts need to be tracked on an ongoing basis. Indeed, a signal that our statute was working would be if the public developed a pejorative noun, other than "rapist," to refer to a person who engaged in culpably reckless sexual behaviorsomething akin to a "drunk driver."

c) The program. Ideally, the new crime of reckless sexual conduct should be a part of a larger private and public effort to eliminate unprotected first-time sexual encounters. While some may view social norms as beyond the reach of policy engineering, we are heartened by the dramatic impact of Mothers Against Drunk Driving (MADD).

213 See Baker, 110 Harv $L$ Rev at 589 (cited in note 181). 1991).

214 Joseph P. Fried, St. John's Juror Tells of Doubts in Assault Case, NY Times A24 (Sept 14,

215 Acquaintance rape can be more devastating in part because it is more of a betrayal of trust. See Jean O'Gorman Hughes and Bernice Resnick Sandler, Friends Raping Friends: Could It Happen to You?, online at http://www.bernicesandler.com/id46.htm (visited Feb 20, 2005). 
MADD became a political force in the early $1980 \mathrm{~s}^{216}$ In just a few years, MADD had successfully lobbied in state after state for tougher drunk driving laws. In 1984, Congress responded by requiring all states to raise the drinking age to twenty-one as a condition of receiving highway money. ${ }^{217}$ MADD, as a grassroots organization, realized that its power came from public awareness. It was MADD that popularized the concept of "designated drivers" and the first red ribbon campaign (asking people to "tie one on" for safe driving) ${ }^{218}$ MADD's slogan is "the Voice of the Victim," but they succeed in large part because they dramatically put a face on the victims of recidivist drunk drivers. ${ }^{219}$

Inspired by MADD's example, it would be useful for public and private groups to put a face on the victims of reckless sex. There already is a Mothers Against Sexual Abuse, ${ }^{20}$ but it would be useful to develop a group that highlighted the STD victims of reckless sex. The idea is to show the people who are injured by reckless sex and the people who did the injuring. Who killed Rock Hudson? And who did Rock Hudson kill? This effort would be part of a larger campaign to valorize protected first-time sexual encounters. ${ }^{21}$

We would see the passage of the reckless sex statute as part of an incremental process of reinforcing norms of condoms and communication for first-time sexual encounters. Starting with more lenient punishment will make it easier to generate more convictions. More convictions will make the risk of unprotected first-time sexual encounters more salient. Once the current norm starts to shift even more strongly toward condom use so that it is truly abnormal to not take the time to put on a condom, it will become easier to punish, and punish more severely, those transgressors. Just as with drunk driving laws, it may well become possible to have stronger second-generation punish-

216 Janice Lord, Really MADD: Looking Back at 20 Years, Driven Mag (Spring 2000), online at http://www.madd.org/aboutus/0,1056,1686,00.html (visited Feb 20, 2005).

217 See Faye A. Silas, Drinking Curb: Highway Money at Stake, 70 ABA J 35 (Nov 1984).

218 Lord, Really MADD, Driven Mag (cited in note 216). See also Kyle Ward, MADD's Telemarketing: Successes and Cautions, 23 Fund Raising Mgmt 26 (1992) (highlighting MADD's telemarketing techniques to increase awareness of the problems related to drunk driving).

219 See Frank J. Weed, Grass-Roots Activism and the Drunk Driving Issue: A Survey of $M A D D$ Chapters, 9 L \& Policy 259, 260-63 (1987) (discussing the development of MADD into a significant political player). 2005).

220 See Mothers Against Sexual Abuse, http://www.againstsexualabuse.org (visited Feb 20,

221 As mentioned above, a message of "just be like everyone else" can be powerfully persuasive. It might also be useful to change the social meaning of condom use. Instead of (or in addition to) the message that men who don't wear condoms in first-time sexual encounters are "jerks," it might be useful to send the message that men who do use condoms are cool or virile. Celebrities (appropriately picked to target different populations) could endorse condom use as a way to "be like me." 
ments. "We just got carried away"223 will not be a defense to the crime of reckless sexual conduct. Once people accept the illegitimacy of that defense for a crime of recklessness, it will become increasingly illegitimate as a defense to rape as well.

\section{RESPONDING TO CONSTITUTIONAL OBJECTIONS}

The last Part showed from a triumvirate of perspectives why criminalizing reckless sex is likely to make progress on the social problems of both STDs and acquaintance rape. There remains, however, the issue of whether our proposed statute is constitutional. In this Part, we consider questions of whether our affirmative defense violates the Due Process Clause and whether the statute's more general regulation of sexuality unconstitutionally burdens the rights of privacy and freedom of association.

\section{A. Constitutionality of the Affirmative Defense}

The affirmative defense afforded defendants is amply supported as a matter of public policy. First, as discussed above, this defense gives women who are the victims of nonconsensual sex more freedom to come forward and report the crime to police. ${ }^{224}$ Second, the difficulty of proving nonconsent beyond a reasonable doubt makes the reallocation of the burden more appropriate. ${ }^{225}$ Indeed, the state of Washington already allocates the burden of presenting and proving the issue of

222 See Anne T. McCartt and Veronika Shabanova Northrup, Enhanced Sanctions for Higher BACs: Evaluation of Minnesota's High-BAC Law, National Highway Traffic Safety Administration Technical Summary (May 2004), online at http://www.nhtsa.dot.gov/people/injury/ alcohol/EnhancedSanctions/pages/TechnicalSummary.html (visited Feb 20, 2005) (noting that since 1990 states have been toughening their punishments for DWI offenders, and as of January 2002 , thirty-one states have statutes or regulations that provided for more severe sanctions of DWI offenders with high blood-alcohol concentration).

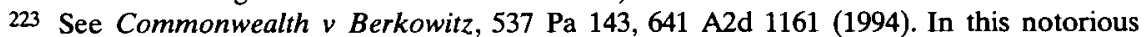
acquaintance rape case, both parties agreed that after intercourse the defendant commented, "We got carried away." The alleged victim responded, "No, you got carried away." Id at 1163. The Supreme Court of Pennsylvania overturned the conviction because there was insufficient evidence to prove beyond a reasonable doubt that she did not consent. Id at 1166.

224 See text accompanying note 171.

225 When the information necessary to prove an element is particularly difficult for the prosecution to obtain, it may be appropriate to shift the burden to the defendant. See Model Penal Code $\$ 1.12$, comment at 194 (noting that "the need for narrowing the issue coupled with the relative accessibility of evidence to the defendant warrants calling upon him" to meet the burden of persuasion). For instance, in corporate criminal prosecutions, the Model Penal Code allocates the burden of proving due diligence to defendant corporations, instead of forcing the prosecution to prove the lack of due diligence beyond a reasonable doubt. See Model Penal Code $\S 2.07(5)$. 
consent to the defendant in (far more serious) rape cases. ${ }^{226}$ Third, putting the burden of proving nonconsent on the prosecution in cases involving unprotected first-time sexual encounters would encode in the law a presumption that women willingly put their physical and emotional health at extreme risk. It would assume that women act recklessly unless the prosecution can prove otherwise. It makes far more sense to assume that no one acts recklessly, unless the prosecution can prove beyond a reasonable doubt that unprotected sex happened. At that point, instead of assuming that the person most likely to be hurt by the reckless behavior was reckless, the law should require the person with the least to lose ${ }^{27}$ and the most to gain ${ }^{228}$ from the reckless behavior to show that his partner willingly consented to the risk.

Regardless of the policy arguments in favor of an affirmative defense, however, it is important to separately address whether the defense accords with the demands of the Constitution. The Due Process Clause demands that a prosecution prove "beyond a reasonable doubt every fact necessary to constitute the crime ... charged."229

As many scholars have recognized, this constitutional command is ripe for legislative manipulation. Because the prosecution must prove beyond a reasonable doubt only those facts that are "necessary to constitute a crime," legislatures can reallocate any element of a crime as an affirmative defense so long as it engages in "arid formalism. ${ }^{, 200}$ Statutes can come to define smaller and smaller subsets of elements as being necessary for conviction. In Patterson v New York, the Court recognized this problem, commenting that the Constitution "may seem to permit state legislatures to reallocate burdens of proof

226 See State v Camara, 113 Wash 2d 631, 781 P2d 483 (1989) (holding that the prosecution has the burden of proving "forcible compulsion" beyond a reasonable doubt, but the defendant has the burden of proving consent by a preponderance of evidence).

227 Men are much less at risk of STD transmission and rape and not at all at risk for pregnancy. See Part I.A.1.

228 See Mary Rogers Gillmore, et al, Heterosexually Active Men's Beliefs About Methods for Preventing Sexually Transmitted Diseases, 35 Perspectives Sexual \& Reproductive Health 121, 127 (2003) ("[M]en nonetheless held several negative beliefs about condom use even with casual partners."); Alan Guttmacher Institute, In Their Own Right at 55 (cited in note 16) ("[M]en's opinions about the condom are not all positive. Many complain that it reduces their sexual pleasure. Some men find it embarrassing to buy condoms or put one on in front of their partner. Others dislike having to discuss condom use before sex."). Men also consider sexual experience an attribute. It gives young men a greater sense of control over their lives. Importantly, it has the opposite effect on women. See Daniel J. Whitaker, Kim S. Miller, and Leslie F. Clark, Reconceptualizing Adolescent Sexual Behavior: Beyond Did They or Didn't They?, 32 Fam Planning Perspectives $111,116(2000)$.

229 In re Winship, 397 US 358, 364 (1970).

230 Charles R. Nesson, Rationality, Presumptions, and Judicial Comment: A Response to Professor Allen, 94 Harv L Rev 1574, 1577 (1981).

231432 US 197 (1977). 
by labeling as affirmative defenses at least some elements of the crime now defined in their statutes. ${ }^{, 232}$ In famous dicta, the Court cautioned, "[T]here are obviously constitutional limits beyond which the States may not go in this regard."233

The question for us is whether the proposed statute can shift the burden of proving consent to the defendant and still stay within those constitutional limits. We think there is little doubt that it can, for one simple reason: Our statute does not criminalize what rape statutes criminalize. Our statute criminalizes unprotected sex. Rape statutes criminalize nonconsensual sex. We have not found one rape statute that even mentions unprotected sex. The crime of reckless sexual conduct therefore could not be a lesser included offense to the crime of rape. It would be perfectly possible to be guilty of rape, but not guilty under our statute. Our statute also imposes a significantly less severe punishment than does rape-and for a good reason. The crime of reckless sexual conduct is not about punishing nonconsensual sex; it is about punishing the less egregious acts involved in an unprotected first-time sexual encounter.

As we noted previously, a strict liability offense, which would remove consent from the analysis completely, could readily be justified as necessary for public health reasons. If the analysis of Part I is correct, merely inducing condom use in first-time sexual encounters can effectively destroy the transmission networks of many STDs and consequently put an end to epidemics. Independent of any concern with consent, there is a strong policy rationale for criminalizing all firsttime sexual encounters that are unprotected.

From this perspective, the affirmative defense is nothing like an essential element of the crime. We are not merely shifting a traditional element of rape from the prosecutor to the defendant. Rather, the defendant must show that the other party consented to unprotected sex. The scope of the defense reinforces the fact that the statute is directed to the problem of controlling STDs.

The affirmative defense lets an accused point to factors that mitigate or extenuate his culpability. While a man who participates in an unprotected first-time sexual encounter is criminally reckless, he is less culpable if his partner actively solicited the unprotected sex. ${ }^{234}$

232 Id at 210.

233 Id. See also Speiser v Randall, 357 US 513, 523 (1958) (cited in Patterson for the principle that a state's statutory definition of a crime cannot "offend[] some principle of justice so rooted in the traditions and conscience of our people as to be ranked as fundamental").

234 The scope of the affirmative defense in the proposed statute goes beyond solicitation to cover defendants who can show that their partner "gave unequivocal indications of affirmatively consenting to engage in sexual activity that is specifically unprotected." But the enlargement of 
Thus, our affirmative defense parallels the affirmative defenses of entrapment and irresistible impulse-defenses that qualify society's condemnation of the defendant's state of mind.

We have included a defense of consent both because, somewhat counterintuitively, it makes it more likely that acquaintance rape will be prosecuted, and because consent qualifies the perceived egregiousness of the defendant's behavior. A consent defense also encourages conversation and protects the sexual freedom of those couples who want to engage in unprotected sex. By encouraging communication our statute guards against acquaintance rape, but nonconsensual sex is not the target of our statute.

\section{B. Burdening Privacy and Associational Freedom}

Finally, we assess whether the statute unduly burdens the constitutional rights of privacy and associational freedom. We do not contest that our statute represents a new restriction on sexual expression. Indeed, where once the state used criminal statutes to impede the distribution of birth control, ${ }^{236}$ we are now using criminal law to mandate it. But our restrictions do not infringe on the constitutional rights of sexual expression as they have emerged to date.

First, it is important to keep in mind that most forms of expression are subject to reasonable time, place, and manner restrictions. ${ }^{237}$

solicitations to include unequivocal indications is consistent both with the notion of lenity and with the idea that not all solicitations are verbal. While other (much maligned) rules have drawn a bright line requiring verbal communication, see Antioch College, Sexual Offense Prevention Policy (cited in note 136), we think it possible that nonverbal cues can act as sufficient indicia of unequivocal consent.

235 To the extent our statute regulates unprotected sex that could not pose a public health threat (between two people who knew they were not STD carriers), our statute imposes an unnecessary health regulation. This is an amazingly small set of first-time encounter pairs. Few people about to engage in a first-time sexual encounter can be sure that the other person is free of STD infections. See Simpson and Gangestad, $60 \mathrm{~J}$ Personality \& Soc Psychology at 872 (cited in note 10). It is only for this small group of people that the statute might be seen as regulating the same thing as rape statutes because the only reason to require such couples to use protection is to protect against nonconsensual sex. This class of cases is so minute and the cost of compliance is so small (get consent or use a condom) that we think it extraordinarily unlikely that it could be seen to violate constitutional guarantees of due process. Overinclusive criminal statutes are not forbidden by the Constitution.

236 See, for example, Tileston v Ullman, 129 Conn 84, 26 A2d 582, 588 (1942) (approving as constitutional laws that criminalize using, or assisting, abetting, or counseling for the use of, contraceptives). This general line of cases has been overturned by the Supreme Court's decisions in Griswold v Connecticut, 381 US 479 (1965), and Eisenstadt v Baird, 405 US 438 (1972).

237 Ward $v$ Rock Against Racism, 491 US 781 (1989) (upholding a city's sound amplification guideline regulating the volume of amplified music in a park amphitheater); Roth $v$ United States, 354 US 476, 512 (1957) (Douglas dissenting) ("There is nothing in the Constitution which forbids Congress from using its power over the mails to proscribe conduct on the grounds of good morals. No one would suggest that the First Amendment permits nudity in public places, adultery, and other phases of sexual misconduct."). 
Our statute regulates the manner in which people are able to participate in a first-time sexual encounter. All we require is that the couple actually discuss (or otherwise communicate about) the issue of protection so that they can be clear that if the expression is to be unprotected, both parties agree to it. There are virtually no long-term consequences that flow from this restriction, and it is hard to see how this could be considered unreasonable in any circumstances. ${ }^{238}$

Second, it bears repeating that this is a one-time-per-relationship health regulation. It does not impose any kind of regulation on an ongoing intimate relationship. We readily accept that sexual relations can be an important means of enriching and nurturing a relationship. The Supreme Court has now endorsed this view unequivocally, ${ }^{239}$ but when it has protected sexual expression, the Supreme Court has done so as a way of protecting and fostering the relationship in which it is being expressed, rather than the expression itself. ${ }^{201}$ The parties' relationship is not unduly burdened when the parties are free either to agree to unprotected sex or to engage in unprotected sex after just one encounter. The sexual liberties that are constitutionally protected from state interference ${ }^{241}$-"the realm of personal liberty which the government may not enter, ${ }^{, 42}$ - are simply not implicated by a statute that only affects first-time sexual encounters.

Third, the behavior regulated here can cause significant harm, in part despite and in part because of its intimate nature. In striking down the Texas sodomy statute in Lawrence $v$ Texas, ${ }^{243}$ Justice Kennedy was careful to point out that a general sodomy statute does not

238 This is particularly true given the extensive historical support for criminally regulating many more aspects of sexual expression, including statutes that regulate who one could have sex with (adultery), how one could have sex (sodomy), and when one could have sex (fornication).

239 See Lawrence $v$ Texas, 539 US 558, 567 (2003).

240 See Griswold, 381 US at 486 ("[Marriage] is an association that promotes a way of life, not causes; a harmony in living, not political faiths; a bilateral loyalty, not commercial or social projects. Yet it is an association for as noble a purpose as any involved in our prior decisions."); Bowers v Hardwick, 478 US 186, 205 (1985) (Blackmun dissenting) (stating that the Court protects relationships because "[they] contribute[] so powerfully to the happiness of individuals"); Lawrence, 539 US at 567 ("When sexuality finds overt expression in intimate conduct with another person, the conduct can be but one element in a personal bond that is more enduring."). Even Eisenstadt, 405 US 438, which upheld the right of unmarried people to use birth control, did so only to the extent that "married and unmarried persons [were] similarly situated." Id at 454. Thus, one cannot read Eisenstadt in isolation from Griswold, and Griswold's right to sexual privacy was clearly grounded in a celebration of the relationship (marriage) in which it was expressed.

241 See, for example, Lawrence, 539 US at 579 (striking down a Texas antisodomy statute as unconstitutional); Eisenstadt, 405 US at 454-55 (extending birth control privileges to unmarried persons); Griswold, 381 US at 484-86 (establishing the right of privacy that allows married people to use birth control).

242 Planned Parenthood of Southeastern Pennsylvania v Casey, 505 US 833, 847 (1992).

243539 US 558 (2003). 
target "persons who might be injured or coerced or who are situated in relationships where consent might not be easily refused." ${ }^{24}$ Unprotected first-time sexual encounters involve precisely all of those dangers. The proposed statute is a minimally intrusive means of guarding against those dangers.

Nonetheless, there may be certain populations that are particularly affected by this regulation. Those who routinely engage in casual sexual encounters, and particularly those who embrace the importance of casual sexual encounters to their sexual identity, will be more burdened than others by this regulation. We recognize that portions of the gay male population are likely to be disproportionately burdened. In a recent survey of sexual behavior in a well-known gay Chicago neighborhood, researchers found that 43 percent of men said that they had had more than sixty sexual partners. ${ }^{245}$ Another 18 percent had between thirty-one and sixty partners and another 27 percent had between sixteen and thirty partners. ${ }^{246}$ This means that 88 percent of this urban gay male population has well over the average number of lifetime sexual partners. ${ }^{247}$ Obviously these men will have more than the average number of first-time sexual encounters. Moreover, the same researchers noted that most "men-seeking-men" personal advertisements in the neighborhood "identify casual sex rather than long-term relationships as their goal. ${ }^{248}$ This means that the proposed statute will necessarily restrict the lives of gay men much more than the norm both because gay men tend to have more sexual partners than is the norm and because gay men tend to prefer casual sexual encounters more than is the norm. Moreover, this preference for casual sex may well be a preference that gays classify as an important part of their sexual identity. ${ }^{249}$

As discussed, and notwithstanding the advent of queer theory, it is unlikely that one could read even the most expansive Supreme Court

244 Id at 561.

245 Stephen Ellingson and Kirby Schroeder, Race and the Construction of Same-Sex Sex Markets in Four Chicago Neighborhoods, in Edward O. Laumann, et al, eds, The Sexual Organization of the City 93, 108 table 4.3 (Chicago 2004).

246 Id.

247 Eighty-six percent of the gay male population lives in metropolitan areas, so these figures may be fairly representative of gay men generally. See Tavia Simmons and Martin O'Connell, Married-Couple and Unmarried-Partner Households: 2000, Census 2000 Special Reports 2 (2003), online at www.census.gov/prod/2003pubs/censr-5.pdf (visited Feb 20, 2005).

248 Ellingson and Schroeder, Race and the Construction of Same-Sex Markets in Four Chicago Neighborhoods at 106 (cited in note 245).

249 See Michael Warner, The Trouble with Normal: Sex, Politics, and the Ethics of Queer Life 25-37 (Free Press 1999) (identifying casual sex with shame and arguing that queer culture is valuable precisely because "at its best [it] has always been rooted in a queer ethic of dignity in shame"). 
case on sexual expression ${ }^{250}$ as protecting the importance of casual sexual encounters to one's sexual identity. That certain groups value a practice does not give that practice constitutional protection. More importantly, our statute does not regulate casual sex, per se. We remain agnostic on the question of whether casual sex is good and an important part of some people's sexual identity. We do not remain agnostic on whether undiscussed, unprotected casual sex is good. Unprotected first-time sexual encounters are incredibly dangerous, not only for the participants, but for anyone who will come into unprotected sexual contact with those participants. ${ }^{251}$ Neither privacy nor associational rights will be "unduly burdened" by its reasonable regulation.

\section{CONCLUSION}

Let us return to the discussion of Star, based on the recent prosecution of Kobe Bryant. The dismissal with prejudice of Bryant's case underscores the need for the regulation of reckless sexual conduct. The dismissal sends a message to the world that what happened in that resort was "just" a one night stand. So it may have been, but even if it was "only that," it was a reckless, dangerous sexual encounter and it was abnormal. Most people now use condoms for one night stands. Those who do not use condoms run the risk of seriously endangering their partners, both physically and emotionally.

Currently, the law's regulation of reckless sexual conduct is sporadic at best. While there is some prosecution of people who recklessly infect others with HIV, there is almost no regulation of the reckless infliction of other STDs and, save rape, there is no regulation of the reckless infliction of the emotional harm that can flow from careless sexual behavior. Comparably, while there is some indirect legal acknowledgement that condoms or the lack thereof may speak to the issue of consent, and while there is de facto recognition that first-time sexual encounters are more easily regulated than subsequent sexual encounters, the law has yet to regulate unprotected first-time sexual encounters in any kind of comprehensive way. This deficiency in the law exists despite the fact that unprotected first-time sexual encoun-

250 See generally Lawrence, 539 US 558.

251 Surveys of different communities indicate that particular groups are remarkably likely to be having sex with more than one partner. Thirty-nine percent of men in one community reported having concurrent sexual partners, and 47 percent of that community's men reported having multiple partners in the last twelve months, while only 20 percent of women in that community reported having multiple partners in the last twelve months. See Laumann, Sexual Organization of the City at 176 table $6.1,59$ table 2.5A, 61 table 2.5B (cited in note 245).

252 The "undue burden" test was developed in another constitutional privacy case. See Casey, 505 US at 877. 
ters are likely the locus of the lion's share of both STD transmission and acquaintance rape.

Our statute fills that gaping hole. Giving men a new incentive to wear a condom in first-time sexual encounters should significantly reduce both the risk of sexually transmitted infections and the tragic lack of communication that often gives rise to the illusion of consent. Because so many first-time encounters are not followed by subsequent sexual encounters, and because just a few people with many unprotected sexual encounters can be so powerful in spreading STDs, a law that requires protection in first-time sexual encounters will be very effective at reducing the spread of STDs. Because so many acquaintance rapes are first-time sexual encounters, and because so many of those rapes are primarily caused by a lack of communication, a law that fosters communication in first-time sexual encounters will likely be very effective at reducing the incidence of acquaintance rape. Our proposal is such a law.

Some readers have wondered whether it is somehow a weakness that the statute makes progress on both the problems of STDs and acquaintance rape. They may sense that we have constructed a thaumatrope, ${ }^{233}$ which by blending these two policy objectives somehow tricks the reader into seeing a whole that is greater than the parts. Let us be clear that our statute is crafted primarily to respond to the important (and gendered) problem of STDs. The essential elements of the crime are tailored to this problem; the affirmative defense, which focuses on consent to unprotected sex, addresses this problem. The fact that this public health statute also makes progress on the serious problem of acquaintance rape should hardly be taken as a deficiency. Just as important, we believe strongly that the prevalence of both STDs and acquaintance rape stems from the same problem: a cultural resistance to public examination of the dangers of sexual activity. Failure to appreciate those dangers leads to recklessness, which in turn leads to both STD transmission and acquaintance rape. Thus, it makes sense to address both problems at once. Moreover, trying to tackle the problem of STDs without incorporating the lessons we have learned from acquaintance rape prosecutions and/or without thinking through the implications for acquaintance rape prosecution would likely produce either an ineffective or a dangerous statute.

253 Webster's New International Dictionary 2616 (Merriam 2d ed unabridged 1954) defines "thaumatrope" as:

An optical instrument or toy for showing the persistence of an impression upon the eye. It consists of a card having on its opposite faces different designs, as figures of a bird and a cage, which, when the card is whirled rapidly round a diameter by the strings that hold it, appear to the eye combined in a single picture, as of a bird in its cage. 
We have argued that three different analytical approachesrational actor, cognitive bias, and norms analysis-support our claim that the proposed statute should reduce the risk of both STD transmission and acquaintance rape. This consilience should give public health specialists and rape reformers added confidence in the statute.

In some sense, our statutory proposal is a provocation. The idea of criminalizing any additional dimension of sexual activity is abhorrent to many readers. But this Article has made two independent claims: (1) increasing condom use in first-time encounters would substantially reduce the force of STD epidemics and the prevalence of acquaintance rape, and (2) our proposed criminal statute is an efficacious method of increasing condom use in first-time encounters. Even if you ultimately reject our second claim about the utility of criminalization, we hope that you will nonetheless accept that enhancing condom use in first-time encounters is a worthy policy goal. Changing behavior in a small fraction of human sexuality can pay huge social dividends. Making many more people aware of the dangers of sexual activity will very likely reduce the prevalence of both physical and emotional sexual injury. Thus, even if criminalization is not the answer, this Article suggests that other social policies aimed at promoting condom use in first-time sexual encounters-programs such as public service announcements, educational programs, or civil penaltiesshould be taken very seriously.

We are all hurt by a world in which sex is reduced to a base, noncommunicative physical act. We are all hurt by a world in which the number of people infected with STDs reaches epidemic proportions. People across the political spectrum can agree that unprotected casual sex does little good for anyone and has the potential to do much harm. A crime of reckless sex, by encouraging people to protect themselves and their sexual partners, can encourage deliberation and communication in ways that promote public health and greatly reduce unnecessary and damaging sexual violence. 